\title{
WestVirginiaUniversity
}

THE RESEARCH REPOSITORY @ WVU

Graduate Theses, Dissertations, and Problem Reports

2007

\section{Student nagging behavior in the college classroom}

Katie Neary Dunleavy

West Virginia University

Follow this and additional works at: https://researchrepository.wvu.edu/etd

\section{Recommended Citation}

Dunleavy, Katie Neary, "Student nagging behavior in the college classroom" (2007). Graduate Theses, Dissertations, and Problem Reports. 2568.

https://researchrepository.wvu.edu/etd/2568

This Dissertation is protected by copyright and/or related rights. It has been brought to you by the The Research Repository @ WVU with permission from the rights-holder(s). You are free to use this Dissertation in any way that is permitted by the copyright and related rights legislation that applies to your use. For other uses you must obtain permission from the rights-holder(s) directly, unless additional rights are indicated by a Creative Commons license in the record and/ or on the work itself. This Dissertation has been accepted for inclusion in WVU Graduate Theses, Dissertations, and Problem Reports collection by an authorized administrator of The Research Repository @ WVU.

For more information, please contact researchrepository@mail.wvu.edu. 


\title{
Student Nagging Behavior in the College Classroom
}

\author{
Katie Neary Dunleavy
}

Dissertation
Submitted to the Eberly College of Arts and Sciences
at
West Virginia University
in partial fulfillment of the requirements
for the degree of
Doctor of Philosophy
in
Communication Studies

\author{
Matthew M. Martin, Ph.D., Chair \\ Maria Brann, Ph.D. \\ Melanie Booth-Butterfield, Ph.D. \\ Richard Walls, Ed.D. \\ Keith Weber, Ed.D.
}

Department of Communication Studies

Morgantown, West Virginia

2007

Keywords: Instructional communication, nagging, Politeness theory, persuasion

Copyright 2007 Katie Neary Dunleavy 


\section{ABSTRACT \\ Student Nagging Behavior in the College Classroom Katie Neary Dunleavy}

Nagging is a persuasive tactic yet to be fully explored in instructional communication. Nagging involves an exchange in which a student makes persistent requests of an instructor who fails to comply. The purpose of this dissertation was to examine nagging in the college classroom in order to ensure nagging was not just an aspect of other instructional concepts. The purpose was also to determine why students choose to nag, to examine the strategies students use to nag, and to examine the perceptions of students and instructors of these strategies. Finally, the purpose was also to examine nagging as a potentially face threatening act as a part of Politeness Theory. Three studies were conducted to explore these problems: study one was conducted using focus group discussions, study two was conducted using an open ended response format in addition to quantitative measures, and study three was conducted using quantitative measures that were completed by both students and instructors. Students report nagging for four different reasons: instructor-related, education-related, affect-related, and preferencerelated. An earlier typology was modified, and it was found students use seven strategies in order to nag instructors: suggest instructor incompetence, demonstrate frustrations with the instructor, elicit student support, strike a deal, barrage instructor with requests, flatter instructor, and elicit sympathy. Nagging is positively related to three other constructs (persistence, compliance gaining, and student challenge behavior) but still remains a separate construct. Nagging is more threatening to the positive face of both students and instructors than negative face, with the elicit sympathy nag the most threatening to the 
students' positive face, and the demonstrate frustration with the instructor nag the most threatening to the instructors' positive face. The majority of these face threatening acts are committed off record, or indirectly, and with a degree of ambiguity. While student and instructor perceptions of nagging frequency do not often significantly differ, students perceive all nagging strategies to be significantly more effective and appropriate than instructors. 
ABSTRACT

ACKNOWLEDGMENTS

CHAPTER I: INTRODUCTION..........................................

Summary of Nagging Research...................................... 3

Nagging Interactions.......................................... 4

Nagging in Marriages........................................... 7

Nagging in Advertising .................................... 8

Nagging in the Classroom...................................... 9

Related Persuasive Constructs...................................... 12

Compliance gaining........................................... 12

Complaining.............................................. 15

Demand/Withdraw........................................... 18

Related Constructs in the Classroom.................................... 22

Student Misbehaviors...................................... 22

Student Resistance.......................................... 25

Student Challenge Behavior...................................... 27

Politeness Theory ..................................................... 29

Overview...................................................... 29

Committing Face Threatening Acts........................... 31

Statement of Problem................................................... 35

Study One.................................................. 35

Research Question One................................. 36

Research Question Two................................. 36

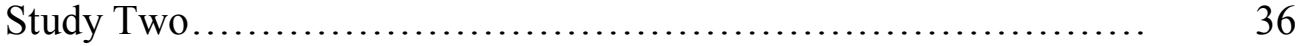

Research Question Three................................ 38

Research Question Four................................. 39

Hypothesis One........................................ 39

Research Question Five................................... 40

Research Question Six................................. 40

Hypothesis Two..................................... 41

Research Question Seven............................. 42

Hypothesis Three........................................ 43

Hypothesis Four....................................... 43

Hypothesis Five ...................................... 43

Study Three.................................................... 43

Research Question Eight.................................... 44

Research Question Nine................................. 45

Research Question Ten.................................. 45

Research Question Eleven............................. 46 
Summary.

Research Question Twelve............................. $\quad 46$

CHAPTER II: METHOD ........................................... 47

Study One................................................... 47

Participants.......................................... 47

Procedure............................................... 47

Data Analysis......................................... 48

Study Two................................................. 49

Participants......................................... 49

Procedures.......................................... 49

Measures............................................... 50

Study Three................................................. 54

Participants.......................................... 54

Measures............................................. 55

Procedures............................................. 55

Summary ................................................. 56

CHAPTER III: RESULTS.......................................... 57

Study One................................................ 57

Study Two.................................................. 63

Study Three................................................ 69

Summary.............................................. 76

CHAPTER IV: DISCUSSION..................................... 77

Limitations................................................... 102

Future Directions.............................................. 103

Conclusion.................................................. 105

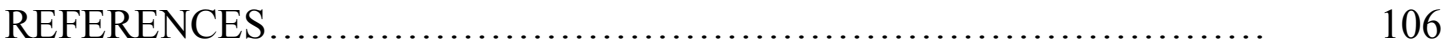

APPENDIXES....................................................... 115

A Questions Used in Focus Group Discussions................. 115

B Survey for Study Two.................................. 117

C Survey for Study Three................................. 123 


\section{LIST OF TABLES}

Page

Table 1. Examples of Face Threatening Acts and Strategies............... 52

Table 2. Face Threatening Acts as a Function of Student Nagging Behavior... $\quad 65$

Table 3. Strategies of Committing Face Threatening Acts as a Function of

Student Nagging Behavior................................... 68

Table 4. Student and Instructor Mean Scores for the Frequency, Effectiveness, and Appropriateness of Nagging Strategies..................... 


\section{ACKNOWLEDGEMENTS}

First and foremost I need to thank my committee members: Maria, Melanie, Scott, Dick, and Keith. You, and the rest of the department at WVU, have made obtaining this degree enjoyable. Unlike most people I know in graduate school, I am always happy to go to the office and (usually) happy to do work, and I attribute it to working with people who are always willing to help and motivate me.

Maria: thank you for teaching me aspects of communication completely foreign to me and for cheering me on during our races.

Melanie: thank you for showing me how to become a better instructor and sticking with me through the process of completing two degrees.

Scott: thank you for teaching me to be more precise (I know I still have a long way to go) and for passing good gossip and celebrity magazines on to me.

Dick: thank you for helping me begin my doctorate and for staying with me when I went in another direction.

Keith: thank you for all the times you stopped what you were doing to help me with stats and for explaining football to me.

Above all, I want to thank my advisor, Matt, for not only agreeing to be my advisor but for helping me with all aspects of grad school. There is little I have accomplished in the last couple of years that you were not apart of. When I felt unmotivated and stupid you helped me feel more confident and appreciative of what was already accomplished. Thank you also for celebrating with me whether it was for school, convention, football, basketball, or just a Friday. 
I also want to thank the other students who went through this process with me, especially Alan and Carrie. Alan, you are the best office mate I could have; you don't care if I like the office dark, if I want to listen to angry music, or if I am cranky for no good reason. Carrie, I always know you are right down the road or a phone call away if I need anything; I hope you know I will be there for you in the same way. Good luck to you both in the future!

I need to thank my mom and dad for supporting me in everything that I do. Mom: I always know that you are behind every decision I make, which makes everything I do seem easier. Dad: I know my education took a lot longer than I originally thought, so I thank you for supporting my decision and helping me through this.

"You're the piece of gold that flashes on my soul" - Thank you 


\section{Chapter I}

\section{Introduction}

The term nagging often is used in conversations to describe, or accuse, the behavior of a person. Nagging behavior can be annoying to the receivers of nags; however, individuals who nag believe their behavior is a demonstration of their concern (Tannen, 1990). The miscommunication that occurs when an individual uses nagging behavior can be problematic for interpersonal relationships (Soule, 2001). While research has examined topics related to nagging such as compliance gaining (Boster, Kazoleas, Levine, Rogan, \& Kang, 1995; Boster, Mitchell, Lapinski, Cooper, Orrego, \& Reinke, 1999; Cody \& McLaughlin, 1980; Grant, King, \& Behnke, 1994; King, 2001), complaining (Alberts, 1988; Alicke, et al., 1996), persistence (Ifert \& Roloff, 1996a; 1996b; Pruitt, Parker, \& Mikolic, 1997), and demand/withdraw patterns of communication (Caughlin, 2002; Caughlin \& Malis, 2004a, 2004b; Caughlin \& Vangelisti, 1999, 2000; Verhofstadt, Buysee, DeClercq, \& Goodwin, 2005; Weger, 2005), research with a focus on nagging behavior has been rare (Dunleavy \& Myers, 2006; Kozloff, 1988; McNeal, 1992; Soule, 2001). Conceptualizations of these related areas may serve as a guide to discern nagging behaviors from other persuasive constructs, making it less difficult to research nagging.

It is also important to differentiate the outcomes of nagging depending on the context in which the behavior occurs. Soule (2001) previously explored nagging in interpersonal relationships (i.e., marriages). McNeal (1992) explored nagging for the purpose of advertising. Nagging also has been studied in counseling (Rowan, 1997; 
Yoshioka, Thomas, \& Ager, 1992) and organizational research (McManus, 2002). It is unknown whether nagging in these contexts is similar to nagging in classrooms because of the power differentials and interdependence differences between the individuals communicating in these contexts (Frymier \& Houser, 2000; Soule, 2006).

None of the research studies identified above provide a conceptualization of nagging that distinguishes it from other related persuasive tactics. However, Soule (2001) did make three generalizations of nagging in marriages. The first generalization is nagging is characterized by persistence (Ifert \& Roloff, 1996b; Soule, 2001). The persistent quality suggests the nagger will continue to make requests even when the respondent resists. The second generalization of nagging is the refrain from escalation (Soule, 2001). Persistence often can lead to the engagement of violence, particularly for men (deTurck, 1987; Ifert \& Roloff, 1996b; Pruitt, et al., 1997). However, when persistence becomes violent, persistence is no longer characterized as nagging, it is then termed the rebuff phenomenon (Soule, 2001; 2006). The third generalization concerns the sex and gender associated with nagging. Nagging is commonly assumed, and originally studied, as a behavior unique to women (Rowan, 1997; Tannen, 1990). There are two explanations for this assumption. The first explanation is that men tend to resort towards more aggression quickly, a demonstration of the rebuff phenomenon (Soule, 2006). The second explanation is the power differential between men and women, which may lead women to acquiesce more quickly, which inhibits men from having to nag. While recent research does not support a sex difference in the use of nagging, nagging is perceived to be a feminine trait (Soule, 2001; 2006). 
Nagging was conceptualized by Dunleavy and Myers (2006) as "pestering others with demands, pleas, and/or requests for compliance when they (instructors) are not doing what we (students) would like them to do" (p. 2). This conceptualization was developed using the descriptions of nagging provided by McNeal (1992), Rowan (1997), and McManus (2002). The conceptualization focuses on nagging in the instructional context.

Based on research related to concepts similar to nagging, and nagging research itself, nagging behavior is defined in this study as an exchange in which a person makes persistent, non-aggressive requests which contain the same content to a respondent who fails to comply. This definition underscores the persuasive and continuous quality of nagging and also emphasizes the exchange that occurs between the initiator and the respondent. This definition in this study differs from the conceptualization provided by Dunleavy and Myers (2006) because it is more useful in distinguishing nagging from other persuasive constructs.

The purpose of this chapter is to review how nagging can be examined in the college classroom. First, previous nagging research will be summarized. Second, related persuasive constructs will be summarized. Third, Politeness Theory (Brown \& Levinson, 1987) will be proposed as a framework for studying nagging behavior. Fourth, a rationale for research questions and hypotheses will be proposed for learning more about nagging in the instructional setting.

Summary of Nagging Research 
The following section is intended to provide more detail about previous studies which examined the nagging construct. These studies describe the exchange process of nagging and the contexts in which nagging occur.

\section{Nagging Interactions}

The most thorough description of the nagging exchange is provided by Kozloff (1988). He described various types of exchanges that are productive or counterproductive to being effective in the classroom and with clients. One type of exchange described by Kozloff was rewarding noncompliance, a term synonymous with nagging. The patterns of communication that become nagging exchanges occur because of the influence that interactants have over one another. According to Kozloff, "each type of exchange 'produces' specific changes in the exchange partners" (p. 6). Individuals have a degree of control over their own communication patterns; however, their conversational partners also have influence. Unfortunately, those individuals who reward noncompliance (i.e., allow themselves to be nagged) reaffirm the nagging behavior, which is often the opposite intent. Therefore, nagging is positively reinforced by compliance, and compliance is negatively reinforced by the reduction of nagging (Christensen, 1988; Kozloff, 1988).

Of the exchanges described by Kozloff (1988), rewarding noncompliance is the most frequently used counterproductive type of exchange. Rewarding noncompliance consists of "one person (a) doing something that is aversive to the other person and being rewarded for it, and/or (b) failing to provide the other with opportunities, assists or rewarding consequences for the other's desirable behavior" (p. 60). The process of 
rewarding noncompliance involves at least five steps. In the first step, a person (the initiator) gives another a signal to perform a specific behavior, which the respondent does not comply with in the second step.

There are a variety of reasons why a person would refuse to comply. The person may not have been paying attention, the message may have been too vague or too long, the message may have evoked some feelings that caused a lack of attention, or the person simply may have felt it was too difficult to comply (Kozloff, 1988). The refusal to comply may be explicit or implicit, but a message is sent that there will not be compliance.

In the third step, after receiving the message of noncompliance, the nagger has three options: persistence, seeking out another target, and abandoning the request (Johnson, Roloff, \& Riffee, 2004b). For the exchange to be considered nagging, the requester must persist. Therefore, in the third step, the initiator repeats the signal (Kozloff, 1988). There are two factors affecting the requester's decision to persist. The first factor is the perceived legitimacy of the request and the refusal. If the nagger believes the request for behavior change was valid, and the failure to comply was not valid, the potential for persistence increases (Johnson, et al., 2004b). The second factor involves the skill needed to overcome the resistance. If the nagger believes it is possible, another nagging message will be created.

At this point, although the initiator's signal has not been met with compliance, the initiator has received some attention. The initiator may perceive this attention as the ability to gain control over the receiver. Another finding supports this notion; individuals perceive nagging to be more powerful than powerless behavior (Soule, 2001). 
The fourth step involves another refusal to comply. In the fifth step, the process continues again and will continue until the initiator abandons the request or the respondent accommodates. To explain how this exchange can lead to the larger behavior patterns, Kozloff(1988) stated that if respondents accommodate, the rewarding noncompliance exchange is reinforced. The next time a situation arises, the initiator will be more likely to attempt to nag because of being rewarded for nagging in the past.

In the exchange of nagging behavior, steps two and four involve the noncompliant response, which may be explicit or implicit (Kozloff, 1988). There are three obstacles that can be expressed verbally (explicitly) when refusing to comply (Johnson, Roloff, \& Riffee, 2004a; Wilson, Aleman, \& Leatham, 1998). The first obstacle is an expression of unwillingness, in which a person refuses because of a lack of motivation. The second obstacle is an expression of imposition, in which a person refuses because of other commitments or because the request is inconvenient. The third obstacle is an expression of a lack of skills and/or resources. This obstacle occurs when individuals refuse because they do not have the ability to comply. These obstacles can be used singularly or in a combination (Ifert \& Roloff, 1996a; Wilson, et al., 1998). Whether the nagger decides to persist may depend on the obstacle expressed by the respondent.

Expressions of unwillingness are most likely to be met with continued persistence (Johnson, et al., 2004a). Continued persistence is particularly true for intimate relationships because a nagger will more than likely perceive the request as more legitimate if uttered by a close relational partner. Expressions of unwillingness not only cause the nagger to persist but also will cause the nagger to make more inquiries into the reasons for refusal. It is unknown if these responses differ in nonintimate relationships, 
such as would be experienced in the classroom. These three verbal responses are not the only approaches that a respondent can take, but they do provide a preliminary outline of what could lead to more persistent behavior.

\section{Nagging in Marriages}

In an exploratory study of interpersonal nagging, Soule (2001) asked married couples to identify the behaviors they associated with nagging. Asking questions, whining, pleading, demanding, reminding, moaning, hinting, gazing, monitoring, and using guilt trips were all behaviors respondents associated with nagging. The most frequently noted response was that the message was constant and repetitive. Topics that were nagged about included the household, money, personal habits, appearance, health, children, love, work, and time. It was found that the nagging ended when either the nagger abandoned the request or the respondent complied, which supports the pattern of nagging described by Kozloff (1988).

Soule (2001) also explored whether nagging behavior was similar to the construct of complaining. Complaining often is used as a way to vent frustrations or a way to voice concerns (Kowalski, 1996). Individuals who nag attempt to change the behavior of the naggee more so than to vent frustrations in both the initial steps and later steps of exchange (Soule, 2001). The importance of this finding is that nagging is not like complaining. Contrary to what was expected, the intent of nagging is to change the behavior of another more than to vent emotions.

Soule (2001) concluded that the frequency at which a person is nagged will lead to two different outcomes. The first outcome is that the more frequently a person is nagged, the more psychological reactance the person will experience. Psychological 
reactance involves a desire to avoid complying accompanied by aggressive feelings. Nagging, therefore, concerns the nagger's desire for change but if used too frequently, nagging can lead to more resistance, and may cause anger in the receiver. The second outcome is that the more frequently a person is nagged, the more likely the person will attribute the behavior to the source. A receiver may feel guilty when first confronted about a behavior change. However, if the nagger frequently brings the topic to the receiver's attention, the blame shifts. This means that the more frequently individuals are nagged the less guilty they feel and the less they attribute the nagging to themselves. Although nagging in Soule's study was not believed to be a trait-like behavior, a naggee may perceive it as such and fail to feel guilty about not complying.

\section{Nagging in Advertising}

Nagging behavior also has been examined in the context of advertising, specifically children's nagging behaviors (McNeal, 1992). Advertisers recognized that children nag their parents, and this behavior can lead to parents complying with their children's pleas. Advertisers wanted to elicit the nagging behavior in children in order to sell more of the product. Schlosser (2002) developed a typology of children's nagging behaviors which included seven nags: pleading, persistent, forceful, demonstrative, sugar-coated, threatening, and pity.

A pleading nag involves repeating a word or phrase, such as "please" or "mom." A persistent nag involves constant requests; the wording may change, making this type of nag different from the pleading nag, but the content remains the same. Forceful nags are often described as pushy and are occasionally accompanied by subtle threats, such as suggesting that good behavior will not continue until met with compliance. 
Demonstrative nags are described as the most risky nag, such as when a child throws a tantrum in a public place. Sugar-coated nags are declarations of praise accompanied with promises for good behavior or less nagging. Threatening nags involve vows of hatred, ineffective blackmail attempts, and promises of bad behavior. Pity nags are claims that things will go wrong if met with noncompliance, such as not being as popular in school or not fitting in with others.

According to Schlosser (2002), advertisers attempt to elicit one nag or a combination of nags from children with their advertisements. The goal is for children to nag their parents until they get compliance. The effectiveness of these nags, or the effectiveness of the advertising used to elicit nags, was not investigated. While this typology has some intuitive appeal of how children nag their parents for products, it has not been generalized to any other age group or context.

\section{Nagging in the Classroom}

Dunleavy and Myers (2006) explored nagging behaviors used by college students in the classroom. A conceptualization of nagging was developed in this study along with a typology of eight nagging behaviors: elicit instructor sympathy nag, elicit student support nag, demonstrate frustration with instructor nag, strike a deal nag, challenge instructor authority nag, suggest instructor incompetence nag, flatter instructor nag, and barrage instructor with requests nag.

The elicit sympathy nag is marked by students who engage in a variety of behaviors designed to make the instructor sympathize with students' personal problems, such as self-disclosing about family, health, and work issues. Students mentioned that the majority of their self-disclosures were exaggerations or even lies. This nag was perceived 
as the most appropriate and the most effective. In addition, students perceived that this type of nag was used more frequently than the others.

The elicit student support nag is marked by students who form coalitions in order to state their requests, such as crowding the instructor and planning a confrontation with other students before class begins. Students report nonverbally crowding the space of the instructor in order to exert pressure for change. They also reported speaking together before class to find out if they were in agreement about what changes should be made so that the group could work together to coerce the instructor.

The demonstrate frustration with instructor nag is marked by students who rely on their nonverbal behaviors, such as rolling eyes and moaning loudly. The goal of this nag is often to get the instructor to end class early or quicken the lecture. It was noted that these nags are easily overlooked; the instructor may not notice students' eye behaviors or hear their sighs.

The strike a deal nag is marked by students who bargain with the instructor for some sort of exchange, such as offering to complete favors in exchange for extra credit opportunities. The goal of this nag is often to receive extra points. Students acknowledged the unequal quality of their propositions. They reported offering to complete very little work in exchange for a large amount of points or credit.

The challenge instructor authority nag is marked by students engaging in a variety of misbehaviors which are not appropriate for the college classroom in order to defy the instructor, such as leaving class early and talking during lecture. The intent of this nag was often to get the instructor to change some policy, such as moving back due 
dates. Students mentioned that they would refuse to participate in class as a demonstration of their defiance.

The suggest instructor incompetence nag is marked by students who engage in a variety of behaviors designed to highlight instructor incompetence. Examples of this nag include making suggestions for more effective teaching and verbally disagreeing during lecture. These nags criticize the instructor with the intent of motivating the instructor to change teaching styles or to prepare more for the course.

The flatter instructor nag is marked by students who engage in a variety of behaviors designed to be favorable by the instructor. Examples of this nag include flirting with the instructor and complimenting the instructor. Students reported this nag would be most effective if used throughout the entire semester.

The final nag, barrage instructor with requests nag, is marked by students who constantly make requests for extensions, extra credit, and early dismissal. Several channels are utilized to deliver this message including email, telephone, and out-of-class messages. While the intentions behind the use of this nag varied, students mentioned that they used several of the channels listed above to ensure the instructor did not forget to make some change. Each of these strategies used singularly would not constitute nagging. It is the persistent nature of these strategies that qualifies them as nagging.

The aforementioned research is useful in understanding the concept of nagging. It provides explanations for why individuals nag, the methods used to nag, and some preliminary outcomes of nagging. Based on Dunleavy and Myers (2006) conceptualization of nagging and the results from other nagging studies, three generalizations of nagging can be made. One, it appears that nagging behaviors can be 
found in a variety of relationships, including the classroom. Two, these behaviors can be categorized, and individuals perceive them as occurring with varying frequency, effectiveness, and appropriateness. Three, nagging behavior involves an exchange between an initiator and a respondent, and is characterized by persistence of the initiator.

While these generalizations can be made, there remains a need to distinguish nagging from related constructs, beginning with constructs that involve persuasive tactics that the initiator may use to nag a receiver. Related persuasive tactics include compliance gaining, complaining, and demand/withdraw patterns of communication.

\section{Related Persuasive Constructs}

The following section is intended to describe persuasive tactics that are similar to nagging. Distinguishing nagging from other persuasive constructs aids in further explanation of what nagging behavior is and is not. It also ensures this is a distinct concept and not merely another label for an established construct.

\section{Compliance gaining}

Compliance gaining refers to messages in which a source attempts to induce an individual to enact a behavior the other individual might not perform otherwise (Wheeless, Barraclaugh, \& Stewart, 1983) and is a form of persuasion that occurs in an interpersonal context (Wilson, 2002). Early conceptualizations and typologies of compliance gaining strategies focused only on one message, which is the strategy. This was criticized because it failed to recognize that in actuality it may take several strategies and attempts to gain compliance (deTurck, 1985). It even has been suggested that it is not useful to examine the first strategy used because the requester may not be attentive of the message until after refusal (King, 2001). More recent studies have focused on the 
effectiveness of specific strategies, the intent of the requester, and the options of the target (Boster, et al., 1999; deTurck, 1985; Grant, et al., 1994; King, 2001).

The relationship between the requester and the target will inevitably affect the strategy utilized. The requester must be careful to pick a strategy that is both effective and yet innocuous so as not to harm the relationship (deTurck, 1985). Even if a target complies, certain compliance gaining strategies may compromise long-term relational satisfaction (Grant, et al., 1994). When attempting to gain compliance from a relational partner, requesters use more reward-oriented strategies (i.e., those strategies that indicate to the target that something will be provided in return for compliance) than with strangers (Wilson, 2002). Even when the target is a stranger, a requester will not use threatening tactics in the first attempt to gain compliance (deTurck, 1985). Apparently, individuals are aware that they should be judicious when employing strategies that are not deemed altruistic (e.g., direct, rational, other-benefit).

Nagging is similar to the concept of compliance gaining because both concepts are persuasive tactics in that they attempt to get individuals to do something they would otherwise probably not do. Another similarity between the two concepts involves the role that guilt plays for the respondent. Guilt is defined as "an unpleasant emotional state that arises from the perception that one has acted non-normatively, or that one has failed to act normatively" (Boster, et al., 1999, p. 168). Respondents may feel guilty because they recognize that they did not enact a behavior as they were expected to or as another person wanted.

A requester can gain compliance by enhancing the guilt of the respondent. One compliance gaining strategy in particular, positive self-feeling, is useful in this regard 
(Boster, et al., 1999). This strategy illustrates that the guilt will be relieved if the respondent complies. In general, guilty individuals comply more with requests than those individuals who are not guilty. Respondents to nagging behavior also are influenced by feelings of guilt (Soule, 2001). Individuals who experience guilt are likely to perceive the nagging as legitimate. Legitimacy is important to the nagger because respondents who do not perceive nagging as legitimate begin to make negative attributions about the nagger. Guilt is a motivator for respondents to both compliance gaining and nagging. deTurck (1985) first made the argument that compliance gaining is not always limited to one message or one strategy. While this is supported, it is still possible to gain compliance with one message. Even if a requester is not deliberate in the use of strategies in the first attempt, a respondent can comply with the message. The ability to gain compliance in a single attempt is the major distinction between compliance gaining and nagging. Nagging depends upon an exchange in which the respondent does not comply with the first or the second request (Kozloff, 1988). Nagging is characterized by persistence, and while compliance gaining may have elements of persistence, persistence is not required. In addition, it appears that when compliance gaining becomes persistent, the strategies used evolve greatly (Boster, et al., 1999; King, 2001). In many instances, these strategies become more hostile and negative (Grant, et al., 1994; King, 2001). As previously mentioned, nagging behavior ceases to be labeled as such when the behaviors move towards aggression, both verbal and physical.

A final difference between the two concepts is that compliance gaining is associated more often with men (deTurck, 1987; King, 2001) whereas nagging is associated with women and femininity (Christensen, 1988; Rowan, 1997; Soule, 2001). 
Men use more compliance-gaining strategies, and they also use more negative strategies (deTurck, 1987; King, 2001).

A second persuasive construct related to nagging behavior is complaining. Similar to compliance gaining, complaining is characterized by behaviors that are related and unrelated to nagging. These comparisons will be discussed in the following section.

\section{Complaining}

Complaining is defined as an "expression of dissatisfaction, whether subjectively experienced or not, for the purpose of venting emotions or achieving intrapsychic goals, interpersonal goals, or both" (Kowalski, 1996, p. 180). An important distinction made in this definition is the addition of intrapsychic and interpersonal goals. Intrapsychic goals involve those which mentally make a person feel better. This is often discussed as venting emotions. Venting emotions does not entail constructive conversations in which problems are solved. Rather, venting is used to release emotions that are causing stress to an individual (Kowalski, 1996). Venting emotions is only one reason why a person may complain, as it is possible that a person complains in order to deflect judgments and to gain attention. However, it should be noted that Kowalski reported that approximately $75 \%$ of complaints are stated to vent frustrations.

Interpersonal goals, the second type of complaining goal, involve distancing a person from someone or something (Kowalski, 1996). By complaining with this goal, an individual can demonstrate superiority or disagreement. For instance, a person could complain as a way to demonstrate disapproval with the workplace, or family life.

Individuals report making complaints an average of four times a day, which are categorized as either being reflexive or ostensive (Alicke, et al., 1992). Reflexive 
complaints are about oneself, such as complaining about hunger, pain, or a failure in achievement. Ostensive complaints are outside of the self, such as complaining about another person or situation.

As with compliance gaining, there are similarities between the concepts of complaining and nagging. These similarities all relate to the reasons why a person would resort to using complaints or nags. One reason why a person complains is to blast another person (Kowalski, 1996). Blasting is putting another person down with the intent of making oneself look better (Cialdini \& Richardson, 1980). A person may complain about the mess a roommate left behind in order to downplay his or her own mess. Blasting is also a reason for nagging behavior to occur. Students nag in order to highlight teacher incompetence and to challenge the teacher, oftentimes to downplay their own poor performances in the classroom (Dunleavy \& Myers, 2006). Another reason for complaints is excuse-making (Kowalski, 1996). Individuals complain as a way of expressing excuses for their behavior, which is also seen in nagging behavior. Students nag in order to inform teachers of the problems that prevent them from getting work done properly or on time (Dunleavy \& Myers, 2006).

Although overlap between the two concepts exists, there are four distinctions between nagging and complaining. The first way that nagging differs involves the intrapsychic dimension described in the definition of complaining. According to Kowalski (1996), “complaints may also be voiced not to change another's behavior but rather to change the complainer's internal state, thereby serving an intrapsychic function" (p. 185). This is termed catharsis. Catharsis is a way of reducing negative affect and rumination, both of which can be troubling to the person with those thoughts (Kowalski). 
Research focused on nagging behavior clearly demonstrates that nagging was not utilized as a way to vent, but to change behavior (Soule, 2001). Nagging is very different from complaints which are often made about situations in which the individual realizes there is no possibility for change (Alicke, et al., 1992).

The second distinction involves the two categories of complaining, which are reflexive and ostensive (Alicke, et al., 1992). Upon examination of the nagging strategies, it is evident that nagging cannot be reflexive. It is not possible for a person to nag about oneself, and the reason for this may have to do with the venting of frustrations. Nagging is not used to vent, so there would be no reason for a person to nag oneself. The behavior change would come about or it would not. Any verbal statement about wanting to change one's own behavior would be labeled as a complaint. It was noted that complaints are more often ostensive than reflexive, but the two types do exist (Kowalski, 1996). Finally, neither type indicates a persistent quality, which is essential to nagging communication. One statement could accomplish the goal of complaining (Alberts, 1988), but a series of statements is necessary in order for a behavior to be described as nagging (Kowalski, 1996; Kozloff, 1988; Soule, 2001).

The third distinction involves two interpersonal reasons for why a person voices complaints which do not apply to nagging behavior (Kowalski, 1996). Complaining may be used as an outlet to discuss positive events. For instance, a student may complain about the hours spent studying for a test which received a high score. The student complains about the time lost but only as a strategy to discuss a good grade. Complaining may also be used for social comparison. For instance, a student may complain about a grade to a classmate with the hope that the classmate will self disclose in return. This 
allows the student to compare grades without having to directly ask for the information. Nagging does not function in the same manner for either of these reasons. Nagging and complaining are indirect methods of initiating conversations, however nagging is direct. Nagging another person is not a way to innocuously or inconspicuously initiate a topic.

The fourth distinction involves the response of the receiver. In one typology, nine verbal statements were reported that a receiver could use in response to complaints: agreeing, disagreeing, justifications, denial, sympathy, problem solving, counter complaints, noncommittal statements, and passing (Alicke, et al., 1992). Many of these same responses were reported by Alberts (1988). The most common response is agreement, in which the respondent concurs with the complaint. Agreement as a response is different from nagging because responses to nagging are far more often nonverbal in nature (Kozloff, 1988; Soule, 2001). In addition, some of the statements in response to complaining are compliant, such as agreeing and sympathy. Responses to nagging are inherently noncompliant, otherwise the exchange of nagging could not continue. The differences in types of messages, reasons for the messages and responses to the messages demonstrate that complaining and nagging are not the same construct. However, another construct similar to nagging that does acknowledge the importance of exchange, although in a different manner, is the demand/withdraw pattern of communication.

Demand/Withdraw Patterns of Communication

Demand/withdraw communication is defined as "a complimentary pattern of interaction in which one partner attempts to advance a conflict, while the other partner attempts to avoid the discussion" (Weger, 2005, p. 22). This type of communication is typically explained from a systems perspective because the behaviors cannot be 
understood singularly; the behavior of one communicative partner is conditional to the behavior of the other. Researchers occasionally use the term nagging synonymously with the demand/withdraw pattern (Caughlin, 2002; Caughlin \& Malis, 2004a, 2004b; Christensen, 1988). Although Soule (2001) also contended nagging was a type of demand/withdraw communication, no demand/withdraw research has either measured nagging or explained the similarities and/or differences between the two concepts. The application of nagging to demand/withdraw research has merit, however, because of similarities beginning with the exchange that occurs in demand/withdraw and nagging. In demand/withdraw patterns and nagging, one person assumes a more aggressive, persistent role.

Demand/withdraw patterns are considered disconfirming (Weger, 2005).

Disconfirming messages involve communication that demonstrates a lack of concern and understanding of one's partner. Demand/withdraw is disconfirming because one individual views a situation as important and worthy of argument, however the relational partner does not. Instead of responding with dissent, the partner responds with indifference, which shows a lack of concern. This communication pattern has received the most attention in the martial relationship (Caughlin, 2002; Caughlin \& Vangelisti, 1999, 2000; Verhofstadt, et al., 2005), however, it does exist in non-romantic relationships (Caughlin \& Malis, 2004a, 2004b). Results consistently associate dissatisfaction with the demand/withdraw communication no matter the type of relationship in which the exchange occurred (Caughlin, 2002; Caughlin \& Malis, 2004a; Christensen, 1988). 
Nagging and demand/withdraw communication also have similar assumptions about sex differences. Much like nagging behavior, the aggressor in the demand/withdraw pattern often is perceived to be women, and men are often the respondents to the behavior (Caughlin \& Vangelisti, 1999; Christensen, 1988; Soule, 2001). The reason for the assumption may be due to the heightened degree of emotional involvement that women experience in their relationships compared to men (Verhofstadt, et al., 2005). The demanding behavior of women is associated with the need for intimacy, whereas the withdrawing behavior of men is associated with the need for independence (Christensen, 1988). These sex differences were found only in marital partners; it is unclear whether these differences will exist in platonic relationships, such as the relationship between the student and the teacher.

Although the nagger and demander are similar, differences are observed when examining the respondent. Respondents to demand/withdraw are concerned only with the avoidance of the situation, mostly due to feelings of indifference (Weger, 2005). For some of these respondents, acting as the demander causes too much emotional arousal which contributes to the desire of avoiding the situation (Verhofstadt, et al., 2005). In some situations nagging can be categorized as a demand/withdraw interaction, but this is not always the case. Respondents to nagging are not always attempting to avoid the confrontation; their intent is to avoid behavioral compliance (Kozloff, 1988; Soule, 2001). In addition, the reactions to nagging are not always indifferent. Some responses are more forceful, particularly if the respondent is experiencing the psychological reactance due to the frequency at which the person was nagged (Soule, 2001). The pattern of exchange is the major difference between nagging and demand/withdraw. 
A final difference between the two concepts involves the outcome of the communication. While demand/withdraw patterns are considered disconfirming, nagging has yet to be labeled as such (Weger, 2005). This disconfirmation is the main response of the withdrawer, which leads to dissatisfaction with the relationship (Caughlin, 2002; Caughlin \& Malis, 2004a; Caughlin \& Vangelisti, 1999). While certain types of nagging may not be perceived as an appropriate or effective way of communicating, they are not always detrimental to the relationship (Dunleavy \& Myers, 2006; Soule, 2001). Demand/withdraw and nagging have some general similarities, however differences exist regarding the response and the outcome of the communication. As with compliance gaining and complaining, demand/withdraw is a separate concept from nagging behaviors. However, similarities exist in nagging exchanges in which the naggee is unresponsive and demand/withdraw patterns of communication. Although the concept of nagging is different from demand/withdraw, nagging is considered one form of demand/withdraw communication (Soule, 2001).

The aforementioned discussions of nagging all centered on constructs related to nagging behavior. Compliance gaining and nagging are persuasive tactics used to change behavior. However, compliance gaining can be accomplished with one message (Cody \& McLaughlin, 1980). Nagging involves at least five stages of exchange (Kozloff, 1988). Complaining often is used synonymously with nagging, however the majority of complaints are made to vent frustrations (Kowalski, 1996). Nagging is not used to vent frustrations; it is used to change behavior (Soule, 2001). Demand/withdraw is a form of exchange similar to nagging in that one person is more insistent and the other responds in the opposite manner (Caughlin, 2002). However, not all respondents to nagging are 
submissive, or withdrawn. Overlap between these constructs exists, but nagging has emerged as a distinct concept.

Compliance gaining, complaining, and demand/withdraw patterns of communication relate to nagging in general. None of the constructs focus on one specific context. In these contexts, nagging may have negative social consequences and yet the nagger resolves to persist. "Instead of honoring the refusal, the requester keeps pressing the target at the risk of creating psychological reactance or escalating conflict" (Ifert \& Roloff, 1996b, p. 40). As was evident in the discussions of demand/withdraw, it is important to also focus on the ways in which the respondent can contribute to the nagging behavior. Kozloff (1988) outlined the basic exchange of rewarding noncompliance in any context, but it is necessary to provide a more thorough explanation of this nagging behavior as it occurs in the classroom.

\section{Related Constructs in the Classroom}

There are three constructs researched specifically in the context of the classroom that are useful in further defining the concept of student nagging behaviors. These three constructs are student misbehaviors, student resistance, and student challenge behavior. Student Misbehaviors

Student misbehaviors include any action performed by the student that interferes with the learning process (Kearney \& Plax, 1992; Plax, Kearney, \& Tucker, 1986). These misbehaviors can be described as active or passive. Active misbehaviors directly disrupt learning, such as when a student talks or plays with a cell phone during lecture. Passive misbehaviors are more covert. They are often difficult for the instructor to detect, such as students having apathy toward the course. Students acknowledge the impact of their 
misbehaviors. They attribute their misbehaviors as the number one reason why instructors become upset and are aware that the misbehaviors may cause the instructor to react emotionally (McPherson \& Young, 2004).

Due to the disruptive nature of misbehaviors, instructors can respond with classroom management behaviors that suppress both active and passive forms of student misbehavior. Classroom management includes "teacher behaviors which produce high levels of student involvement in classroom activities, minimal amounts of student behaviors that interfere with the teacher's or student's work, and efficient use of instructional time" (Emmer \& Evertson, 1981, p. 342). A method of classroom management is behavior alteration techniques (BATs); prosocial BATs are enacted to counter passive student misbehaviors and antisocial BATs are enacted to counter active student misbehaviors (Kearney \& Plax, 1992; Kearney, Plax, Sorensen, \& Smith, 1988; Plax, et al., 1986).

Like misbehaviors, nagging can disrupt the classroom. One type of nag, demonstrate frustration with the instructor, is enacted as a way to disrupt the classroom to make the student request obvious (Dunleavy \& Myers, 2006). Students may groan, shuffle papers, and begin packing their belongings to request the teacher summarize a point in lecture or to end the class early. Another nag, challenge instructor authority, also is used to disrupt the classroom. If students do not agree with an assignment or grading, they may use this type of nag to demonstrate their control over the classroom. The behavior is used to indicate that the classroom will continue to be disruptive until the students' requests are met with compliance. 
A second way that misbehaviors parallel nagging behavior is through the responses of the instructor. Both of these types of communication cannot fully be understood without examining both the requester (student) and respondent (instructor). The respondent will affect the subsequent message of the requester (Johnson, et al., 2004a, 2004b). For instance, although students attribute their misbehaviors to reasons why instructors become upset, as soon as the instructor reacts fervently and emotionally the student begins to attribute the reaction to the instructor (McPherson \& Young, 2004). It is not yet understood how instructors can respond and promote student nagging behavior, but from previous nagging research it can be assumed that the instructor does have this influence (Kozloff, 1988). For instance, respondents mentioned using the flatter the instructor nag because the instructor indicated that type of nagging was effective (Dunleavy \& Myers, 2006).

Despite the similarities of student misbehaviors and nagging behaviors, there is an important difference that distinguishes the two concepts. The first distinction regards the conceptualization, which isolates misbehaviors to actions that disrupt the classroom (Kearney \& Plax, 1992; Plax, et al., 1986). While some nagging behaviors can disrupt the classroom (e.g. demonstrate frustration, challenge the instructor authority), nagging is not characterized only with behaviors that disrupt the classroom (Dunleavy \& Myers, 2006). Several nags, including the elicit student support and elicit sympathy nags, often occur outside of the classroom. Also, the intention of these nags may not always be to inhibit learning in the classroom, but to promote learning. The suggest instructor incompetence nag, for instance, is often used as a way to request that the instructor spend more time preparing lecture and designing assignments. Although this may not be the most 
appropriate method, the intent behind the use of this nag is to alter instructor behavior for the purpose of making lecture more effective and enjoyable.

\section{Student Resistance}

A second classroom construct related to nagging is student resistance. Student resistance is oppositional behavior; however, this behavior can be destructive or constructive oppositional behavior (Burroughs, Kearney, \& Plax, 1989). Conceptualized this way, student misbehaviors are actually a subset of student resistance, focusing on the destructive oppositional behaviors. Constructive oppositional behaviors promote on-task actions. According to Burroughs, et al. (1989), constructive oppositional behaviors may seem very similar to student compliance. The difference is that with constructive oppositional behaviors the student is not complying with the instructor; rather, the student is defying the instructor. This defiance may push the instructor off-track in lecture. The defiance may actually promote learning, however, if the lecture was not focused on the material. For instance, if an instructor is encouraging distractions, such as leading offtopic discussions, the student can defy the instructor with the intent of returning to the learning material.

There are 19 student resistance strategies, and students vary in their attempts to resist (Burroughs, et al., 1989; Kearney, Plax, \& Burroughs, 1991). Although students comply with their instructors more often than they resist, approximately $21 \%$ of students report using resistance strategies (Burroughs, et al., 1989). Nonverbal resistance strategies are used more often than verbal strategies (Kearney, et al., 1991). Like misbehaviors, students can attribute their resistance to themselves (student-owned) or to the instructor (instructor-owned). These attributions often are made based on the 
behaviors of the instructor. Students report more student-owned blame when the instructor is immediate versus nonimmediate (Kearney, et al.). Differences also are seen in the use of student resistance depending on whether the instructor uses prosocial or antisocial strategies. Interestingly, students use more resistance strategies with instructors that are prosocial (Kearney, et al.). This is explained as the students attempting to justify their own behaviors to a teacher who appears open and caring (Burroughs, et al., 1989). Students will be more likely to attempt to maintain the face of instructors they like and that appear approachable.

Like student resistance, student nagging behaviors can be enacted through several strategies. Nagging and student resistance are related because both sets of strategies can be categorized as constructive or destructive. Nagging behaviors that could be considered constructive are the elicit student support nag, the suggest instructor incompetence nag, and the barrage instructor with requests nag (Dunleavy \& Myers, 2006). These nags could urge the instructor to move the class towards on-task behaviors. Nagging behaviors that could be considered destructive are the challenge instructor authority nag and the demonstrate frustration with instructor nag. In most situations, these nags would move towards off-task behaviors. For instance, one way that a student could enact the challenge instructor authority nag is to walk out of the classroom early. Obviously, if a student is no longer present in the classroom, the on-task behaviors have been disrupted.

The major difference between these two constructs involves the order of exchange. Students use resistance strategies in response to an instructor's attempt to gain compliance. A student can resist an instructor who is attempting to stay focused on the lecture with destructive oppositional behavior, and a student can resist an instructor who 
easily lectures off topic with constructive oppositional behavior. In either situation, the instructor serves as the initiator, or requester, and the student serves as the respondent. Students use nagging behaviors in order to gain compliance from the instructor. In this exchange, the student serves as the initiator and the instructor serves as the respondent. Student Challenge Behavior

The final classroom construct with similarities to student nagging behavior is student challenge behavior. Challenge behavior is defined as a "mediational strategy that students use to share ownership of the classroom culture, which may be motivated by uncertainty, and is manifested by behaviors that are contrary to teacher expectations" (Simonds, 1997, p. 483). Simonds identified four categories of challenge behavior: evaluation, procedural, practicality, and power play challenges. Evaluation challenge behaviors are those in which a student questions the procedures of assessment. Procedural challenge behaviors are those in which a student tests the norms and rules of the classroom. Practicality challenge behaviors are those in which a student questions the relevance of tasks completed in the classroom, or throughout the course. Power play challenge behaviors are those in which a student attempts to influence instructor behavior and/or other student behavior. According to Simonds (1997), these behaviors are not isolated to Communication Studies courses; they are present across several disciplines including math, business, science, education, as well as liberal arts.

Student challenges are similar to student nagging because challenges and nags can be described as inappropriate classroom behaviors for students to enact. Examples of power play student challenges include attempts to embarrass the instructor, interruptions during the instructor's lecture and even threats of harm to the instructor (Simonds, 1997). 
Typically, these are not considered appropriate classroom behaviors by instructors. The inappropriateness of nagging behaviors was previously discussed, and is similar to the power play student challenges (Dunleavy \& Myers, 2006). Student challenges also are similar to student nags because neither are direct responses to instructor behavior; the behaviors initiate a succession of interactions instigated by the student (Dunleavy \& Myers, 2006; Simonds, 1997).

The similarities between these two constructs are not as strong as difference which extends from the conceptualization of challenge behavior as a response to uncertainty. According to Simonds (1997), student challenge behavior is a way for students to gain more certainty in a classroom. Students may be uncertain about implicit rules or norms in the classroom and begin to compare scores with other students (evaluation challenges) or express desires to complete assignments differently than required (procedural challenges). Both of these methods are used to clarify the expectations in order to reduce uncertainty. Students also may be uncertain about explicit rules or norms in the classroom and begin to question the class requirements (practicality challenges) or question the instructor's knowledge (power play challenges). These methods can be used to test the instructor in order to make certain the explicit consequences will be upheld. Again, the important factor in challenge behavior is that the student is acting in response to uncertainty which is not the prevailing factor in a student's decision to nag.

The preceding section has focused on instructional concepts with relation to nagging behavior. Student misbehaviors, student resistance strategies, and student challenge behaviors contribute to understanding the effects of student behavior on the 
climate in the classroom. These constructs are valuable to nagging behaviors because they provide a basis for the potential outcomes of nagging in the classroom. Student misbehaviors are distinct from nagging behavior because they focus only on disruptive behavior, student resistance is distinct from nagging behavior because it only examines students as respondents, and student challenge behaviors are distinct from nagging behavior because challenges are a response to uncertainty.

\section{Politeness Theory}

The purpose of the following section is to propose a potential theory in which to frame nagging behavior. Politeness Theory is useful in demonstrating how communicative acts can harm the face of those involved. Nagging is an act that can harm the face of the speaker and the receiver, making Politeness Theory a possible framework from which to understand nagging further.

\section{Overview}

A theory that could potentially frame nagging behavior is Politeness Theory (Brown \& Levinson, 1987). Politeness theory is derived from Goffman's (1963) conception of face. The theory has a very large scope, making it applicable to numerous contexts even cross-culturally (Craig, Tracy, \& Spisak, 1986; Goldsmith \& Macgeorge, 2000). In the past, Politeness Theory was used to explain compliance gaining, another persuasive construct (Baxter, 1984). According to Brown and Levinson (1987), each person has two types of face: negative and positive. Both types of face can be maintained, enhanced or lost. Negative face is "the want of every 'competent adult member' that his actions be unimpeded by others" (p. 62), which indicates that each individual has a desire to remain autonomous and free from imposition. In the classroom, students can threaten 
the negative face of instructors by asking to meet with them during times that do not correspond with the instructor's office hours. Positive face is "the want of every 'competent adult member' that his wants be desirable to at least some others" (p. 62). This suggests that each individual has desires to be liked, understood, and admired (Brown \& Levinson). Students can threaten the positive face of instructors by suggesting they are incompetent or uncaring of the students.

Individuals are emotionally invested in their faces, and they attempt to reduce incidents in which they could lose face (Brown \& Levinson, 1987). However, whether a person loses, maintains, or enhances face is dependent on others. Not just anyone can satisfy these face wants. Only individuals relevant to particular goals can satisfy these wants. For instance, in the classroom, a student's desire to appear intelligent (a positive face want) cannot always be satisfied by other students. It is more likely that only the instructor can satisfy the student's positive face wants because the instructor is the one who is deemed the expert and who evaluates the learning. Individuals realize that their face wants can only be met through the actions of others and, for this reason, individuals mutually attempt to maintain each other's face (Brown \& Levinson). Occasionally, there are acts that inherently threaten others' positive and negative face; these are called face threatening acts (FTAs).

As individuals usually want to maintain each others face, a conscious decision must be made to commit the FTA. The decision to commit to the FTA is made after weighing three different wants (Brown \& Levinson, 1987). First, there is the want to communicate the FTA. For instance, a student may want to remind an instructor to write a letter of recommendation, even though the instructor has already agreed to write the 
letter. Second, there is the want to be efficient and urgent. The student may feel it is necessary to remind the instructor due to a pending deadline. Third, there is the want to minimize the threat of the FTA to the respondent. The student may understand that the instructor is very busy, and the time taken to write the recommendation can harm the negative face of the instructor. The student also may understand that the reminder suggests the instructor is being inattentive, or inefficient, which can harm the positive face of the instructor. If the student can prepare a message that reduces the potential threat, there is greater likelihood that the message will be sent.

A message does not possess a constant degree of face-threat, which Brown and Levinson (1987) explain with three factors. The first factor that can exacerbate or reduce the level of face-threat is the relationship between the interactants. Typically, the more intimate the relationship, the less face threatening the act (Goldsmith \& Macgeorge, 2000). The second factor is the power differential between the interactants. The more power the speaker has the less face threatening the act (Brown \& Levinson, 1987). As students are in the position of less power, they must be particularly cautious when committing FTAs with their instructors. The third factor is the intrinsic rank of the message, which will be discussed more below. The rank of the FTA is the least examined factor (Goldsmith \& Macgeorge, 2000).

\section{Committing Face Threatening Acts}

Once an individual has committed to delivering a FTA, the severity of the threat can be decided (Brown \& Levinson, 1987). There are four levels of FTAs: bald on record, negative politeness, positive politeness, and off record. The most threatening FTA is 'bald on record,' which is the most clear and direct way of delivering a message with 
the potential to harm another's face (Brown \& Levinson). Bald on record is only used when there is no fear of retribution. That is, a person will only commit to this FTA if there is a small likelihood of the relationship continuing in the future, or if there is little dispute that the FTA was deserved.

The second most threatening FTA is negative politeness (Brown \& Levinson, 1987). This FTA is committed while showing concern for the negative face of the respondent. A student asking for a letter of recommendation may acknowledge the time constraints of the instructor and other, more pressing, duties the instructor must complete. This is mostly done so that the speaker does not feel that the respondent was unfairly coerced.

Positive politeness is the third most threatening FTA, which is also committed to while showing concern for the positive face of the respondent (Brown \& Levinson, 1987). This FTA is delivered in such a way that respondents are made to feel that they have the same wants as the speaker. Students can emphasize the instructor's intelligence and influence while asking for a letter of recommendation.

The least threatening FTA is one that is committed 'off-record' (Brown \& Levinson, 1987). To commit an FTA off-record is to deliver a very indirect message. For instance, the student could mention applying for graduate school with the intent of reminding the instructor of the needed recommendation. While Goldsmith and Macgeorge (2000) did find certain strategies to be more or less intrinsically face threatening, there was not much support for off-record messages as the most polite strategy. Although the desire to maintain face is constant, a speaker will not select a strategy that is more polite than necessary. There are two outcomes of using a more polite 
strategy than necessary. The first outcome is that a more polite strategy will demand more effort than the speaker may be willing to give. The second outcome is that a more polite strategy may imply that the act is more face threatening than it really is (Brown \& Levinson, 1987; Craig, et al., 1986, Goldsmith \& Macgeorge, 2000).

Multiple face threats are possible in one message. A student may demand that an instructor spend extra time explaining an assignment outside of class (negative face) because the instructor was not thorough or clear when explaining the assignment in class (positive face). Wilson, et al., (1998) also revised the original explanation of the way that face threats occur contextually, which suggests that the face threats in the classroom are likely to be enacted and responded to differently than face threats in a marriage.

According to Wilson, et al., (1998), "persons rely on two sources of shared knowledge to identify potential face threats: (a) situational dimensions that define specific influence goals (i.e., what counts as advice or favors) and (b) preconditions that define what always is presumed by seeking compliance (i.e., constitutive rules for directives)" (p. 90). Based on the context, an individual will assess the potential face threats that are likely to occur to save face for both self and other. These two ways of identifying face threats are consistent across demographic differences and relationship differences (Wilson, et al., 1998; Wilson \& Kunkel, 2000). Regardless of these differences, individuals use the same criteria to identify potential face threats.

Reasons often are provided as a person makes a request with the potential to threaten a respondent's face (Wilson \& Kunkel, 2000). These reasons could explain why the respondent should comply. For instance, a student could make an argument for asking the instructor because the instructor has more knowledge and resources than another 
student. The reasons could also justify why the requester is asking in the first place. For instance, a student could explain that the required text for the class is not helping him or her understand the material.

Nagging behavior is inherently a face threatening act for both the speaker and the respondent, making Politeness Theory an appropriate framework for studying nagging. Nagging behavior is threatening to the positive face of the speaker because of the persistent nature of the nag, which suggests the speaker is having difficulty getting the respondent to comply. Nagging behavior also is threatening to the negative face of the speaker because the request can place the speaker in 'debt' to the respondent. Once the respondent complies with the nagging request, the speaker is then implicitly or explicitly indebted to the respondent.

Although the face wants of the speaker are threatened by nagging, it is the face wants of the respondent that are more at risk of damage due to nagging behavior. According to researchers (i.e., Brown \& Levinson, 1987; Wilson, et al., 1998; Wilson \& Kunkel, 2000), any attempts to modify a person's behavior, such as giving orders, requests, suggestions, and warnings will be face threatening. As nagging is conducted as a means to get someone to comply with a request, the behavior change that must occur to comply inherently threatens the negative face of the respondent. These requests for compliance may imply that the nagger has little respect for the respondent and that the nagger is negatively evaluating the respondent, both of which threaten the positive face of the respondent (Brown \& Levinson, 1987).

The inherent nature of nagging to be face threatening makes Politeness Theory of interest to nagging research. The methods which naggers use to minimize the threat of 
nagging to themselves and to respondents are unclear, although it is certain that methods are used because nagging is intentional.

\section{Statement of the Problem}

To further understand student nagging, three studies were conducted. Study one involved a qualitative reexamination of the typology of nagging strategies. Study two examined the relationship between nagging and Politeness Theory. Study two also served as a validation study between nagging and related persuasive constructs. Study three compared instructor and student perspectives of student nagging behavior.

\section{Study One}

A typology of eight strategies to nag instructors was developed in the only instructional study that has investigated nagging behavior (Dunleavy \& Myers, 2006). That study focused on how students nag their instructors. Before moving forward in the exploration of nagging behavior the typology should be reexamined. The purpose of this study was twofold. The first purpose was to examine how students nag their instructors to ensure that the strategies ascertained by Dunleavy and Myers were exhaustive and mutually exclusive. The second purpose of the study was to examine why students nag their instructors. The previous instructional nagging study examined student perceptions of frequency, appropriateness, and effectiveness of nagging but not why students nag. Nagging behavior is used to change the behavior of another, which answers the larger question of why individuals nag. However, the more specific reasons why an individual nags is not known, particularly why students nag in the classroom.

A distinction needs to be made between why students nag and the intended outcome of nagging. Students may nag their instructors in hopes that they will receive 
extra points, find out grades, get out of class early, reduce their workload and to make up assignments; these are intended outcomes of nagging. Outcomes do not explain why students nag their instructors instead of using a one-shot compliance gaining technique or a challenge behavior in order to get their way. Understanding the intended outcomes of nagging also contribute to understanding why students nag their instructors. The two research questions posited in study one were:

RQ1: How do college students nag their instructors?

RQ2: Why do college students nag their instructors?

\section{Study Two}

The purpose of study two was also twofold. The first purpose was to examine Politeness Theory in relation to nagging behavior. The second purpose was to validate the nagging construct. Politeness Theory contends that while conversationalists have a desire to maintain face, there are numerous acts, or messages, that inherently threaten face. According to Brown and Levinson (1987), FTAs can damage four faces in a conversation: the respondent's negative face, the respondent's positive face, the speaker's negative face, and the speaker's positive face. Honoring face is particularly important in persuasive situations; if the receiver's face is lost during the interaction, it is unlikely the request will be met with compliance. In one study, efforts to maintain positive and negative face accounted for $18 \%$ of the variance in the effectiveness of the message (Goldsmith \& Macgeorge, 2000). In this study, it was argued that student nagging behavior has the potential to be threatening to each type of face, and it was the intent of this study to examine this threat and the efforts of students to maintain face. 
Brown and Levinson (1987) broadly described acts that are inherently threatening to the negative face wants of the respondent. First, any act that requires the respondent to do something, or puts pressure on the respondent to do something, will harm negative face. Examples of this type of act include orders, requests, suggestions, remindings, threats and dares. By nagging an instructor, a student is requesting that an instructor do something. The persistent quality of nagging suggests the student is pressuring the teacher to comply with the request. Nagging can therefore be included in this first type of FTA.

A second act that is threatening to the negative face of the respondent is one that is accompanied by threats or promises (Brown \& Levinson, 1987). The strike a deal nagging strategy included in the typology of student nagging behaviors exemplifies this type of FTA (Dunleavy \& Myers, 2006). When students nag by promising good behavior or work or, conversely, when students nag by threatening bad behavior or work, this is threatening to the instructor's negative face.

A final act that threatens an instructor's negative face is one that is accompanied by compliments and expressions of admiration (Brown \& Levinson, 1987). Also included in this act are expressions that display strong emotions tied to the message, such as when a person nonverbally demonstrates how much a request means to him or her. The flatter instructor nagging behavior is one strategy that is therefore threatening (Dunleavy \& Myers, 2006). These three inherently face threatening acts could each be applied to student nagging behavior. Examples from the typology were used above to demonstrate this application, however it is not clear which strategy is inherently the most face threatening to the instructor. For that reason the third research question was posited: 
RQ3: Which nagging strategy is more inherently face threatening to instructors' negative face?

In addition to the potential damage to the negative face of instructors, nagging behavior also may damage the positive face of instructors. According to Brown and Levinson (1987), there are at least two acts that inherently threaten the positive face of respondents. The first act includes any message that expresses a negative evaluation of the respondent. Examples of this act include messages that contain criticism, disapproval, disagreement, or challenges. The suggest instructor incompetence nagging strategy exemplifies this act. Students who employ this strategy are attempting to change instructors' behavior by highlighting their inadequacies (Dunleavy \& Myers, 2006).

The second act that is face threatening to the positive face of instructors includes any message that demonstrates the speaker disregards the feelings of the respondent (Brown \& Levinson, 1987). Conversations in which the speaker mentions inappropriate topics that are emotionally laden for the respondent would demonstrate a disregard. Also, the use of address terms that are inappropriate, such as when a student purposely addresses a professor as "Mister" instead of "Doctor," are demonstrations of disregard. Finally, this act includes any blatant refusal of cooperation. Students who use the suggest instructor incompetence nag or the elicit student support nag are demonstrating their disregard for the instructor, which violates the face wants of the instructor to be respected. Although certain nagging strategies appear to be more inherently threatening to the positive face of instructors, it is not yet known which strategies are the most threatening to instructors. For that reason the fourth research question was posited: 
RQ4: Which nagging strategy is more inherently face threatening to instructors' positive face?

It is proposed in this study that nagging is face threatening to the positive and negative face of both the instructor and the student. In the classroom, nagging interactions pressure the instructor to comply with a request, which is often more time consuming than evaluative of the instructor's behavior. Due to the power distance that characterizes the teacher-student relationship (Frymier \& Houser, 2000), there are fewer instances in which the student will negatively evaluate and harm the positive face of the instructor. Students are aware that to be critical and judgmental of instructors is probably not the best method to coerce an instructor to comply with a request (Sabee \& Wilson, 2005). Student persistence while nagging, however, pressures and constrains the instructor's time, depending on the request. The time required of instructors suggests the negative face of the instructor is more likely to be threatened in a nagging exchange than the positive face of the instructor. For that reason, the first hypothesis was posited:

H1: Instructors' negative face is more likely to be threatened by student nagging than positive face.

While nagging an instructor, students also must be cognizant of the potential damage they may cause to their own face. There is only one broad act that threatens the negative face of students and that is making excuses. Offering excuses is threatening to the negative face of the speaker because it places the speaker in "debt" to the respondent (Brown \& Levinson, 1987). The speaker is admitting some behavior was not performed or not performed to set standards. The speaker is then in "debt" to the respondent, and may have to acquiesce to demands set by the respondent in the future. The strike a deal 
nagging strategy is again useful in exemplifying this act. Students must typically offer an excuse when bargaining with instructors, and this bargain will constrain the student in the future. The threat of other nagging strategies to a students' negative face is not known. For that reason, the fifth research question was posited:

RQ5: Which nagging strategy is more inherently face threatening to students' negative face?

Brown and Levinson (1987) proposed several acts that are inherently threatening to the positive face of speakers. These acts include making apologies, accepting compliments, and making nonverbal errors (e.g., stammering, having emotional leakage). None of these acts are directly pertinent to nagging behavior. The only act that is clearly applicable to nagging behavior is making confessions. Making confessions involves admissions of guilt and/or responsibility (Brown \& Levinson). The elicit sympathy nagging strategy is an example of this type of act. Even if the student indirectly assumes responsibility, such as requesting a later due date because of a family illness, this still has the potential to damage the positive face wants of a student. The student is confessing that he or she is unable to fulfill duties and is now requesting the instructor to aid the situation. How nagging strategies can threaten the positive face of students has yet to be investigated. For that reason, the sixth research question was posited:

RQ6: Which nagging strategy is more inherently face threatening to students' positive face?

Research questions three and four are posited to determine which strategies are more inherently threatening to the negative and positive face of students. It is therefore expected that student nagging is threatening to both types of face. However, it is possible 
that one type is more threatening to students than another. Although students may spend time in their repetitious efforts to nag instructors, the student's positive face may have the potential for more damage. In the classroom, the student's positive face wants include being liked and being perceived as intelligent and capable (Brown \& Levinson, 1987). Students may threaten their desire to be liked by the instructor when they persist with instructors about the same request. Students may also threaten their desires to be perceived as intelligent and capable when they nag because it is evident that they are not able to fulfill these requests on their own. For this reason, the second hypothesis was posited:

H2: Students' positive face is more likely to be threatened by their nagging than negative face.

Sabee and Wilson (2005) conducted a study examining Politeness Theory in the classroom. Specifically, the purpose of that study was to examine students' facework as they discussed disappointing grades with instructors. Students have four primary goals when entering a conversation with instructors about disappointing grades: learning, persuading, fighting, and impressing. Regardless of the goal, discussing disappointing grades is face threatening to students and instructors. The level of FTA (whether it was off-record, negative politeness, positive politeness, or bald on record) was also examined in this study. Students whose primary goal was learning almost entirely avoided the most threatening FTA, bald on record. Of all the goals, students tended to utilize negative politeness the most. This study established that varying types of FTAs are used in the classroom by students, and that these differ depending on the goals students have. 
Based on the results of the Dunleavy and Myers (2006) study of student nagging behaviors, some nagging strategies appear to have higher levels of threat than others. Based on the behaviors used to describe nagging strategies in the typology, the elicit sympathy nag and the flatter instructor nag appear less threatening than the suggest instructor incompetence nag. However, the level of threat these strategies inflict has not yet been examined. For that reason the seventh research question was posited:

RQ7: Will the type of politeness strategy used by students be associated with their nagging strategies?

As previously mentioned, the second major purpose of this study was to provide validity for the nagging construct. There are three aforementioned constructs that could provide concurrent validity for student nagging behavior: persistence, compliance gaining, and student challenge behavior. Persistence is defined as "a voluntary choice to pursue influence goals when facing resistance from a target” (Ifert \& Roloff, 1996b, p. 41). Soule (2001) argued that nagging was similar to persistence. Nagging and persistence involve an intentional decision to pursue an issue with another person and, much like the use of nagging behavior, persistence is used when a respondent refuses requests (Ifert \& Roloff, 1996a, 1996b). Compliance gaining, similar to nagging, is a means of persuasion (Wilson, 2002). Compliance-gaining strategies are varied, as are nagging strategies (Boster, et al., 1999). In addition, when a respondent refuses requests, the compliance gaining becomes more persistent (Ifert \& Roloff, 1996a; King, 2001). Student challenge behaviors could also be useful in establishing convergent validity for the nagging construct. Challenge behaviors are confrontational, as are nagging behaviors, even when not enacted in face-to-face situations (Simonds, 1997; Soule, 2001). Ease in 
confronting instructors would be expected from students who use both challenge and nagging behaviors.

Relationships between persistence, compliance gaining, and challenge behavior with nagging would provide convergent validity to the nagging construct. For that reason, the following hypotheses were posited:

H3: Nagging will be positively related to persistence.

H4: Nagging will be positively related to compliance gaining.

H5: Nagging will be positively related to student challenge behavior.

\section{Study Three}

Another area to be investigated concerning student nagging behavior is the instructor's perception of nagging. There are several areas of interest having to do with the instructor's perception, including the use of nagging strategies, as well as the perceived appropriateness and effectiveness of the strategies. Although nagging is conceptualized to be an intentional method of changing behavior, some of the nagging strategies are more active, such as the suggest instructor incompetence nag and the elicit sympathy nag. A student who questions the capabilities of the instructor, and who discloses personal information, is much more obvious to an instructor than rolling eyes (demonstrate frustration with the instructor) and making comments about how enjoyable the instructor makes the class (flatter the instructor). Nags that are more active are probably recognized by the instructor more, and it is possible that passive strategies could be overlooked altogether. This could lead to miscommunication between the student and instructor because the instructor fails to change behavior due to a lack of stimulation. The purpose of study three was to understand the instructor's perception and evaluation of 
student nagging behavior, which could provide further insight into the effectiveness of nagging in the classroom.

Dunleavy and Myers (2006) assessed students' perceived frequency of the nagging strategies. Students reported the elicit sympathy nag was used with the highest frequency, followed by the strike a deal nag. The challenge instructor authority nag was used significantly less frequency than both the elicit sympathy nag and the barrage instructor with requests nag. Instructors' perceptions were not assessed in the study.

Obtaining the receiver's perception of a communication event is important as some self-reported traits may not be evidenced in behavior seen by the receiver (Cole \& McCroskey, 2003). Martial partners' perceptions of the amount of repetition involved in nagging are associated (Soule, 2001). However, marital partners' reports of the power and femininity of nagging behavior are also associated, which suggests that marital partners may have similar perceptions due to the closeness of the relationship. As nagging has not been investigated in non-familial relationships, it is unclear whether students and instructors will have an association in their report of student nagging behavior. For that reason the eighth research question was posited:

RQ8: Do students and instructors significantly differ in their perceptions of the frequency of student nagging behavior?

Dunleavy and Myers (2006) assessed students' perceptions of the appropriateness and effectiveness of nagging. The students reported that the elicit sympathy nag was the most effective and appropriate nagging strategy. The demonstrate frustration with instructor nag was perceived by students as significantly less effective as the elicit instructor sympathy nag. The barrage instructor with requests nag was perceived as 
significantly more effective than either the demonstrate frustration or the challenge instructor authority nags. Although the suggest instructor competence nag is used with less frequency than many other strategies, it should be noted that this nag was perceived as one of the more effective nags. This does not suggest that these nags are deemed effective or appropriate by the instructor, however. It is important to ascertain the instructor perception of the effectiveness and appropriateness because the instructor may not acquiesce to nagging behavior if it is not considered such. For this reason, the following research questions were posited:

RQ9: Which nagging strategy do instructors perceive as the most effective? RQ10: Which nagging strategy do instructors perceive as the most appropriate?

The teacher-student relationship differs from other interpersonal relationships due to the time constraints and power differential that characterize the relationship (Frymier $\&$ Houser, 2000). These fundamental differences can lead to opposing viewpoints. Student self-perceptions of competence and their actual behavior as reported by others do not appear to be associated (Rubin, Graham, \& Mignerey, 1990). When students are critical of their knowledge and skills, others give them more credit than the students give themselves and vice versa. In addition, students' behaviors can influence their perceptions of instructors' behaviors (Schrodt, 2003). This suggests student perceptions do not always match others' perceptions of behavior in the classroom. This could be problematic for students who utilize nagging strategies. Students who cannot accurately assess which strategies are perceived as effective and appropriate by instructors could place themselves in detrimental situations where they are not only refused compliance, 
they embarrass themselves. To assess the relationship between the student and instructor perception, the final research questions were posited:

RQ11: Do students and instructors significantly differ in their perceptions of the effectiveness of student nagging behavior?

RQ12: Do students and instructors significantly differ in their perceptions of the appropriateness of student nagging behavior?

\section{Summary}

Nagging is defined as an exchange in which a person makes persistent, nonaggressive requests which contain the same content to a respondent who fails to comply. This conceptualization comes from previous research of the nagging exchange (Kozloff, 1988), nagging in contexts (Dunleavy \& Myers, 2006; McNeal, 1992; Soule, 2001), and related persuasive constructs (Alicke, et al., 1992; Boster, et al., 1990; Caughlin, 2002). In order to validate and explore this concept, three studies were conducted. The purpose of these studies was to (a) examine how and why students nag; (b) determine how face threatening nagging is the instructional setting; (c) establish validity with three related constructs (i.e., persistence, compliance gaining, and challenge behavior) and; (d) examine the relationship between instructor and student perspectives on student nagging behavior. 


\section{Chapter II}

\section{Method}

\section{Study One}

Participants. Participants were recruited from introductory communication courses at a large Mid-Atlantic University. Of the 68 participants in the study, 35 were college-aged female students, and the 33 remaining participants were college-aged male students. Participants were led in focus group discussions in mixed-sex groups with an average of 13 participants in each group.

Procedure. Participants were initially contacted about the study in their classroom. The primary researcher informed prospective participants of the location and average time length of the focus groups. Participants were not told the specifics of the study; however they were informed that the study concerned student behavior towards instructors. Participants then signed up for various times and dates.

At the beginning of the focus group sessions, the participants signed consent forms and were given general instructions about focus groups. For instance, they were reminded there are no right answers to any of the questions posed to the group. They were also encouraged to interact with one another and not to direct the conversation to the focus group facilitator only. After the instructions, the tape recorder was shown to the participants. Participants were allowed the option of participating without recording, if they were uncomfortable being recorded. No participants opted to participate without the recording.

After tape recording began, all participants were provided a packet. The packet contained a definition of nagging and examples of each strategy of student nagging. 
Participants were instructed to stay on the same page of the packet as everyone else and not to move forward until asked to do so. The purpose of this was for students to visually see the definitions and examples to aid in their recall of events. After the focus group sessions, the packets were collected.

Sample questions that guided the focus group discussions are included in Appendix A. The focus group discussions lasted an average of 37 minutes. After the sessions, the tapes were transcribed. The transcribed discussions resulted in 68 pages of single-spaced text. As there was no new information introduced in the latter focus groups, it was concluded that saturation was reached (Strauss \& Corbin, 1998).

Data Analysis. The transcripts were analyzed using a grounded theory approach. A lineby-line analysis of open coding was completed first (Strauss \& Corbin, 1998). A codebook was created using the categories that emerged from this open coding. Axial coding was then used to reduce the number of categories. According to Lindlof and Taylor (2002), “axial coding brings previously separate categories together under a principle of integration" (p. 221).

To ensure the reliability of the coding, all transcripts were read and coded by two trained coders who were not familiar with the purpose of the study. Using the provided codebook, the coders analyzed all of the transcripts. This resulted in $70 \%$ agreement with the primary researcher and the first coder, and $71 \%$ agreement with the primary researcher and the second coder. These percentages were considered sufficient to establish inter-coder reliability (Strauss \& Corbin, 1998). 
Study Two

Participants. Participants in the study were 189 students (105 males, 80 females, 4 participants failed to indicate their sex) enrolled at a large, Mid-Atlantic university. The age of participants ranged from 18 to $62(M=19.86, S D=3.53)$. Ninety-three $(49 \%)$ participants were first year students, $38(20 \%)$ were sophomores, 35 (19\%) were juniors, and $19(10 \%)$ were seniors. Four participants did not indicate their status $(2 \%)$.

Participants came from a variety of majors: social sciences (49 participants), business and economics (42 participants), physical sciences (30 participants), biomedical sciences (23 participants), physical education (21 participants), humanities (6 participants), fine arts (4 participants), and education (2 participants). Twelve participants reported an undeclared academic status.

Procedures. Participants were initially contacted about the study in their classroom. The primary researcher informed prospective participants of the location and average time length it would require to participate in the study. Participants were not told the specifics of the study; however they were informed that the study concerned student behavior towards instructors. Participants then signed up for various times and dates.

Once at the testing location, all participants were provided with a cover letter informing them of the study. Participants were told involvement in the study was voluntary and they were free to withdraw at any point. The definition of nagging was read to the participants, and examples of the nagging exchange were explained by the primary researcher.

Each participant was then randomly provided with two survey packets and instructed to complete only one packet. Two packets were provided to supply more 
options to the participants in case one of the packets provided a nagging strategy the participant never utilized. Several participants indicated they could not complete either packet. In those instances, the participants were provided extra survey packets until finding a match. In one instance, a participant indicated he had never nagged an instructor in his academic career. He was then offered the opportunity to participate in a separate study. Thirty participants reported on the elicit sympathy nag (16\%). Twenty-eight participants reported on the strike a deal nag (15\%). Twenty-eight participants reported on the flatter the instructor nag (15\%). Twenty-seven participants reported on the demonstrate frustration with the instructor nag (14\%). Twenty-seven participants reported on the elicit student support nag (14\%). Twenty-six participants reported on the barrage the instructor with requests nag (14\%). Twenty-three participants reported on the suggest instructor incompetence nag (12\%).

Measures. Participants first read a description of one nagging strategy and were then prompted to think about an exchange with an instructor in which they used that nagging strategy. Participants wrote out this exchange, including their own message, and how the instructor responded. The directions for this survey, and all measures for study two, are included in Appendix B.

A coder identified the face threatening acts (FTAs) within the exchange using Brown and Levinson's (1987) list of FTAs: threats to the instructor's negative face, threats to the instructor's positive face, threats to the student's negative face, and threats to the student's positive face. Only student responses provided in the exchange were coded. The part of the exchange that involved instructor responses was not coded because 
the purpose of the study was to examine how student nagging was face threatening. Participants used an average of 2.04 FTAs in each exchange reported $(S D=.83)$.

The same exchange was coded for the politeness strategies used. Type of politeness used while committing a FTA was identified using Brown and Levinson's (1987) list: bald on record, negative politeness, positive politeness, and off record. If no FTAs were indicated in the exchange, they were labeled as non-face threatening. Once again, only student responses provided in the exchange were coded. Examples of the FTAs and the strategies used to commit the FTAs used by the participants appear in Table 1. 
Table 1

Examples of Face Threatening Acts and Strategies

Instructors' Positive Face "We said, 'How can we possibly have a midterm when you haven't taught us anything and we have learned nothing?'"

Instructors' Negative Face 'I sent my professor an email asking for extra help. We had a review session. I still was confused and asked to meet with him again."

Students' Positive Face "I went up to my teacher in class one day and told her I would do my best to finish but I didn't think I could do it in time."

Students' Negative Face "I phrased [the nag] trying to indicate willingness to still work for any extra credit I received."

Bald on Record

"I said, 'When are you finally going to have our tests graded?",

Positive Politeness

"I explained the problem then after that I explained, aside from the problem, how much I enjoyed the class and her as an instructor."

Negative Politeness

"I nagged for a teacher to write a recommendation for me. I continuously said that having a person of his status would definitely benefit me."

Off Record

"I started by questioning the professor, trying to understand what her perspective was. I was saying things like, 'What do you mean by that?" 
After writing out the exchange, the participants then completed several measures. Frequency of nagging behavior was assessed with seven items, one item for each nagging strategy. Following a brief description of each nagging strategy, participants indicated how frequently they used each type of nag with instructors. Responses ranged from (0) never to (4) always. Used as a summative measure of frequency of use, the Chronbach alpha reliability obtained was $.57(M=10.20, S D=4.36)$.

Persistence was assessed with five items that measure the desire to persist (Ifert \& Roloff, 1996b). The first item was slightly modified so that the target was specified as the instructor rather than a more general relational partner. Items are rated using a Likert-type scale ranging from (1) not at all to (5) very much. Chronbach alpha reliabilities of .88 (Johnson, et al., 2004b) and .92 (Ifert \& Roloff, 1996b) have been obtained for this measurement. In the present study, the Chronbach alpha obtained reliability was $.88(M=$ 19.71, $S D=4.49)$

Compliance gaining was assessed with the 16-item Compliance-Gaining Techniques measure (Miller, Boster, Roloff, \& Seibold, 1977). Each item can be used singularly or as a summative scale (Hunter \& Boster, 1987). In this study, the measure was used as a summative scale. Participants read each item and indicated how confident they would feel using each strategy by rating the item from $(0 \%)$ not at all confident to $(100 \%)$ totally confident. A reliability of .81 has been obtained for this summative measurement (Boster \& Levine, 1988). In the present study, the Chronbach alpha reliability obtained was $.85(M=42.39, S D=16.78)$.

Student challenge behavior was assessed with twenty items developed by Simonds (1997). The scale is comprised of five items for each of four dimensions: procedural 
challenges, evaluation challenges, power challenges, and practicality challenges. The measure can be used as a multidimensional measure or a unidimensional measure. In this study, the measure was used as a unidimensional scale. A previous reliability of .90 has been obtained for this unidimensional measurement (Simonds, 1997). In the present study, the obtained reliability was $.83(M=25.97, S D=9.02)$.

\section{Study Three}

Participants. Two sets of participant responses were obtained in study three. The first set of participants was 82 instructors ( 42 males and 40 females) who teach at a large, MidAtlantic university. Seven of the instructors reported themselves as adjunct, 24 of the instructors reported themselves as assistant professors, 17 of the instructors reported themselves as associate professors, 19 of the instructors reported themselves as full professors, and 2 of the instructors reported themselves as emeritus professors. Thirteen participants indicated their status was none of the options listed above. Participants came from a variety of departments: humanities (18 participants), physical sciences (17 participants), social sciences (15 participants), fine arts (8 participants), business and economics (7 participants), education (5 participants) biomedical sciences (2 participants), and physical education (1 participant). Nine participants did not indicate their department. Years of experience as an instructor ranged from 1 to $53(M=15.46$, $S D=11.82)$

The second set of participants was 280 students (149 males, 126 females, and 5 participants who failed to report their sex) enrolled at a large, Mid-Atlantic university. The age of student participants ranged from 18 to $43(M=20.69, S D=2.09)$. Twentynine participants were first year students, 50 were sophomores, 115 were juniors, 78 were 
seniors, and two were graduate students. Six participants failed to report their academic status. Participants came from a variety of majors: social sciences (77 participants), business and economics (65 participants), physical sciences (25 participants), biomedical sciences (23 participants), physical education (21 participants), humanities (11 participants), fine arts (6 participants), and education (4 participants). Twenty-six participants reported an undeclared academic status (22 participants failed to indicate their academic status).

Measures. Student nagging strategies were assessed using the typology developed by Dunleavy and Myers (2006), which was modified in study one. Participants were provided with descriptions of each nagging strategy. Following each description were three items. The first item instructed participants to indicate their perception of the frequency of nagging strategy use by students. The item was rated using a Likert-type scale with responses ranging from (1) never to (7) always. The second item instructed participants to indicate their perception of the appropriateness of the nagging strategies. The item was rated using a Likert-type scale with responses ranging from (1) never appropriate to (7) always appropriate. The third item instructed participants to indicate their perception of the effectiveness of these nagging strategies. The item was rated using a Likert-type scale with responses ranging from (1) never effective to (7) always effective. All items from study three are included in Appendix C.

Procedures. The instructor sample was sent a survey packet through campus mail. The packet included a measure of student nagging frequency, student nagging appropriateness and student nagging effectiveness, in addition to demographic information. Instructors interested in participating, completed the survey and returned the survey in a pre- 
addressed envelope through campus mail. Survey packets were distributed to 310 instructors. The response rate of instructors was approximately $27 \%$. Student participants were provided with the same measures included in the instructor packet; however, the students completed packets during one of their scheduled courses. Student participants were told involvement in the study was voluntary and they were free to withdraw at any point.

\section{Summary}

The purpose of chapter two was to provide an overview of the participants, procedures, and measures used to collect data. Data for study one was collected through qualitative measures to validate the strategies of student nagging behavior and to understand why students nag. Data for study two was collected through an open-ended description of a specific nagging exchange and through quantitative measures to explore nagging through a Politeness Theory framework and to validate nagging as a construct. Data for study three was collected through quantitative measures to determine the relationship between student and instructor perceptions of student nagging behavior. The next section provides the results from these methods. 


\section{Chapter III}

Results

\section{Study One}

The first research question asked how students nag their instructors. In a previous study, the typology of nagging strategies consisted of eight categories of student nagging behavior (Dunleavy \& Myers, 2006). In the present study, six of these categories remained unchanged: elicit student support, flatter the instructor, strike a deal, elicit sympathy, barrage with requests, and the demonstrate frustration with the instructor. The remaining two categories from the previous study, challenge instructor authority and suggest instructor incompetence, were combined. The suggest instructor incompetence nag was a stronger category and some behaviors in the challenge instructor authority nag were subsumed into this nag.

Although students provided responses and examples of the challenge instructor authority nag, these responses were minimal. The responses that were provided were often aggressive in nature, both physical and verbal aggression. According to one male student, this behavior includes, "cussing the teacher out. Flippin' over desks and stuff." Another student recalled a time in which she threatened an instructor: "I pretty much just told him I wasn't going to listen to him and said if he wanted to put [a religious debate] on me again that I would have him fired." The problem with these responses is their aggressive nature, which is contradictory to the definition of nagging.

Besides aggression, participants also reported behavior in this category that would not be considered nagging because it did not involve an exchange. For example, when discussing attempts to challenge authority a student said, "With evaluations you can get a 
pretty big complaint if there was enough people having trouble with the class. 'Cause I had a chemistry teacher that... it took people probably 20-30 minutes to write things about her." This is a way of challenging instructor authority, but this is not considered nagging because the student never engages in an exchange with the instructor while writing an anonymous evaluation.

When questioned about other behaviors that could fall into this category, participants either did not have any experiences to relate or they described behaviors that were more aligned with other categories. One category that participants often described when attempting to discuss the challenge instructor authority nag was the suggest instructor incompetence nag. For example, a student commented about her experience with what she considered the challenge instructor authority nag:

We had this history class where this teacher was so awful and she would, like, ask people questions and she was such a bad teacher that no one would know the answer. So people would be like, 'You didn't teach that so we can't answer you.' People would talk back to her... when she asked questions.

This student appeared to describe a nagging exchange, however, these behaviors are much more descriptive of nagging with the suggest instructor incompetence nag. For this reason, a few of the behaviors included in the challenge instructor authority nag were included in the suggest instructor incompetence nag. Behaviors that were included in the category of suggest instructor incompetence were refusing to do work consistently in class and talking during lecture. The suggest instructor incompetence nag, however, was a strong category and continues to be labeled as the suggest instructor incompetence nag, although the description has been expanded to include some of the non-aggressive challenge instructor authority behaviors. 
The second research question asked why students nag their instructors. Four general categories of reasons for nagging emerged from the data: instructor-related reasons, education-related reasons, affect-related reasons, and preference-related reasons. The first category of reasons is instructor-related. Students choose to nag instructors because the instructor fails to respond to requests or responds and yet does not comply. A male participant described his reason for nagging an instructor who promised to allow the student to make up an exam but did not show up at the scheduled time. According to the participant, "the only thing I look at is if [the instructor] could just listen, like one time. Like, the professor could sit there and say, 'this is when you're going to take the test,' and stick by his word. Then I wouldn't be forced to nag." The student felt that the instructor was not being upfront about what needed to be done to makeup work, and he decided to nag in order to remedy the problem. Other students claim that nagging is an important way of dealing with instructors who make arrangements with students and do not keep their word, such as allowing a student to make corrections on a paper and then not increasing the student's grade. The intended outcome of the nagging is to obtain more points, but the reason for nagging is because of a lack of response, or contradictory response, from the instructor.

Students also choose to nag instructors for instructor-related reasons because the instructor encourages and even promotes the behavior. One male participant explained that he nags instructors because of an instructor who suggested students use that persuasive tactic:

The teacher's pretty cool, but he grades each test individually, so he looks at exactly what you answer. And, like, this one kid, he got a terrible grade. He just kept hassling the teacher every day, and the teacher finally broke down and said, 'look, come to my office hours and we'll discuss, you know, what we can do.' So, 
the next day in class they were joking around and [the instructor] was just like, 'see everybody, if you just come in and just discuss it with me, I'll change the grade. Ask Alex.' That's the boy's name. He ended up getting, like, ten extra points on the test.

The students who use this reasoning believe that instructors want to be nagged to make sure that they are doing their job appropriately. As one male participant commented, “they know sometimes there's mistakes grading and they want you to check up on that." It appears that students attribute their nagging to two different types of instructors: those who are unresponsive and those who encourage nagging behavior.

A second category of reasons is education-related. Students choose to nag instructors as a method of clearing up confusion and gaining more knowledge. A female student reasoned that her nagging behavior is used to show the instructor that she is having trouble grasping the material. Her contention is that her difficulties are probably similar to other students. Her nagging would then get the instructor involved so that confusion for all would be reduced.

Other education-related reasons involve demonstrating effort in the classroom. For instance, a female student commented that her nagging behavior exhibits her initiative in the classroom. According to another female student, "it's showing that you really care." The students who use this reasoning find that their nagging behavior carries over throughout the semester and helps them succeed. As one female student stated, it “shows you're interested in [the subject], but also that you're trying hard." A male student summarized this reason for nagging:

If you go in and have a one-on-one conversation with 'em, [the instructor is] going to see that-I mean, you're making an effort. You're not just sitting at your desk. They respect you much more for coming and talking to 'em. 
A third category of reasons is affect-related. Students choose to nag instructors as a way to make the instructor more aware of them as students. For instance, one male participant commented that, "a professor is not going to help you if you're just a name and a number in a huge class. If you go up and, and show them who you are-express it-face-to-face, they're going to do a whole lot more for you." By nagging instructors the students feel that their nagging behavior is preventing them from being as anonymous in class. Instead, the nagging distinguishes them from the crowd. According to a female student, "I think it makes you stand out more. If you would like, email a professor-they know your name but they don't know who you are. As opposed to if you go to office hours and stuff."

Affect-related reasoning also includes students who want to develop a closer relationship with the instructor. Some students find their instructors interesting and believe they could be friends outside of the classroom. It is these students' belief that nagging will allow this relationship to develop. A male student explained his reason for nagging was to "have a good relation with, you know...it's not like a relationship between a teacher and the students. Just friends." Others agreed that nagging was a way to establish a relationship with instructors beyond the formal instructor-student relationship.

A fourth category of reasons is preference-related. Students choose to nag instructors because they find this persuasive tactic preferable to others. Other persuasive tactics participants mentioned included going over the instructor's head to a higher authority and becoming aggressive. Going to higher authorities was considered juvenile behavior; a method that would only get the instructor angry, not to comply. According to 
a female student, "You don't want to make them mad by going over their head."

Aggression, according to the students, is also to be avoided. A female student described her reasoning against aggressive forms of persuasion:

Anytime you get aggressive with them in any form they're gonna act different. So nagging would be like your best way to kinda get your point across

without...potentially get what you want without being aggressive so that they don't, like, hate you.

Nagging is also considered preferable because it serves as a constant reminder to the instructor, which a one-shot strategy such as compliance gaining may not do. A male student commented that he prefers nagging "just so that they remember it. Like, if I have an issue, trying to move tests and stuff like that. If you see it coming up, you mention it then and you mention it again when it gets closer to the time so they have time to think about it and don't forget it." According to a female student, "If you, you know, walk up to them after class chances are they're probably going to forget."

At the same time that these nagging strategies make the instructor more conscious of the students' desires, it remains a "subtle" strategy—a word that several students used to describe the positive attributes of nagging. For instance, one male student commented that, "nagging, like [another participant] said, is the only subtle thing. To sit there and actually get on their case, but be polite about it." In some occasions this may be a forced preference, as students comment there are no other alternatives to this behavior. A male student explained this by saying the instructor is, "the only person you can go see, they're they only one that can do anything about it, or can change it." Occasionally, students believe they do not have the capability of doing anything else to get what they want. Their helplessness, therefore, leads them to nag instructors. 
Study Two

Research questions three, four, five, and six were tested using a multivariate analysis of variance (MANOVA) with four dependent variables: threat to instructor's positive face, threat to instructor's negative face, threat to student's positive face, and threat to student's negative face. The results from the MANOVA indicated there were significant differences in face threat dependent on the nagging strategy, Wilks's $\Lambda=.35$, $F(4,184)=9.18, p<.001$. A series of four ANOVAs were then conducted to determine the independent contributions of the dependent variables.

The third research question asked which nagging strategy was more threatening to the instructor's negative face. The results of the ANOVA were significant, $F(6,180)=$ $5.65, p<.001$. A post hoc Scheffe test indicated those participants reporting on the flatter instructor nag $(M=.68, S D=.90)$ were significantly more threatening to the instructor's negative face than those reporting on the strike a deal nag $(M=.04, S D=19)$ and the elicit sympathy nag $(M=.10, S D=.31)$.

The fourth research question asked which nagging strategy was more face threatening to the instructor's positive face. The results of the ANOVA were significant, $F(6,180)=36.28, p<.001$. A post hoc Scheffe test indicated those participants reporting on the suggest instructor incompetence nag $(M=1.95, S D=.80)$ were significantly more threatening to the instructor's positive face than those participants reporting on the elicit student support nag $(M=.74, S D=.81)$, the strike a deal nag $(M=$ $.18, S D=.61)$, the barrage instructor with requests nag $(M=.27, S D=.60)$, the elicit sympathy nag $(M=.17, S D=.46)$, and the flatter the instructor nag $(M=.18, S D=.39)$. A post hoc Scheffe test indicated those participants reporting on the demonstrate 
frustration with instructor nag $(M=2.04, S D=.1 .09)$ were significantly more threatening to the instructor's positive face than those reporting on the elicit student support nag, the strike a deal nag, the barrage instructor with requests nag, the elicit sympathy nag, and the flatter the instructor nag.

The fifth research question asked which nagging strategy was more face threatening to the student's negative face. The results of the ANOVA were significant, $F$ $(6,180)=4.08, p<.001$. A post hoc Scheffe test indicated those participants reporting on the strike a deal nag $(M=.54, S D=.69)$ were significantly more threatening to the student's negative face than those reporting on the suggest instructor incompetence nag $(M=.05, S D=.22)$, the demonstrate frustration with the instructor nag $(M=.07, S D=$ $.38)$, and the flatter instructor nag $(M=.11, S D=.32)$.

The sixth research question asked which nagging strategy was more face threatening to the student's positive face. The results of the ANOVA were significant, $F$ $(6,180)=7.42, p<.001$. A post hoc Scheffe test indicated those participants reporting on the strike a deal nag $(M=1.11, S D=.92)$ were significantly more threatening to the student's positive face than those reporting on the suggest instructor incompetence nag $(M=.29, S D=.56)$, and the demonstrate frustration with the instructor nag $(M=.26, S D$ $=.53)$. The post hoc test also indicated the elicit sympathy nag $(M=1.30, S D=.75)$ was significantly more threatening to the student's positive face than those reporting on the suggest instructor incompetence nag and the demonstrate frustration with the instructor nag. The results of these four research questions appear in Table 2. 
Table 2

Face Threatening Acts as a Function of Student Nagging Behavior

\begin{tabular}{|c|c|c|c|c|}
\hline \multicolumn{5}{|c|}{ Mean Score } \\
\hline & $\begin{array}{c}\text { Instructors' } \\
\text { Positive Face }\end{array}$ & $\begin{array}{c}\text { Instructors' } \\
\text { Negative Face }\end{array}$ & $\begin{array}{c}\text { Students' } \\
\text { Positive Face }\end{array}$ & $\begin{array}{c}\text { Students' } \\
\text { Negative Face }\end{array}$ \\
\hline $\begin{array}{l}\text { Suggest Instructor } \\
\text { Incompetence }\end{array}$ & $1.95_{\mathrm{a}}$ & $.14_{b}$ & $.27_{\mathrm{ab}}$ & $.05_{\mathrm{ab}}$ \\
\hline $\begin{array}{l}\text { Demonstrate } \\
\text { Frustration }\end{array}$ & $2.04_{\mathrm{a}}$ & $.15_{\mathrm{b}}$ & $.26_{\mathrm{ab}}$ & $.07_{\mathrm{ab}}$ \\
\hline $\begin{array}{l}\text { Elicit Student } \\
\text { Support }\end{array}$ & $.74_{b}$ & $.56_{\mathrm{b}}$ & $.70_{\mathrm{b}}$ & $.15_{\mathrm{b}}$ \\
\hline Strike a Deal & $.18_{\mathrm{b}}$ & $.04_{\mathrm{ab}}$ & $1.11_{\mathrm{bc}}$ & $.57_{\mathrm{bc}}$ \\
\hline $\begin{array}{l}\text { Barrage with } \\
\text { Requests }\end{array}$ & $.27_{\mathrm{b}}$ & $.50_{\mathrm{b}}$ & $.92_{\mathrm{b}}$ & $.23_{\mathrm{b}}$ \\
\hline Elicit Sympathy & $.17_{\mathrm{b}}$ & $.10_{\mathrm{ab}}$ & $1.30_{\mathrm{bc}}$ & $.17_{\mathrm{b}}$ \\
\hline $\begin{array}{l}\text { Flatter the } \\
\text { Instructor }\end{array}$ & $.18_{\mathrm{b}}$ & $.68_{\mathrm{bc}}$ & $.82_{b}$ & $.11_{\mathrm{ab}}$ \\
\hline$F$ & $36.28 *$ & $5.65^{*}$ & $7.42 *$ & $4.08^{*}$ \\
\hline
\end{tabular}

Note: Suggest instructor incompetence $=21$ participants. Demonstrate frustration $=27$

participants. Elicit student support $=27$ participants. Strike a deal $=28$ participants. Barrage with requests $=26$. Elicit sympathy $=30$. Flatter the instructor $=28$. Means not sharing subscripts along each column are significantly different from each other. ${ }^{*} p<.001$. 
The first hypothesis posited that the instructors' negative face was more likely to be threatened by nagging behavior than the instructors' positive face. This hypothesis was not supported. The results of t-test indicated the instructors' positive face is more likely to be threatened by nagging than the instructors' negative face, $t(186)=6.91, p<$ .001 .

The second hypothesis posited that students' positive face was more likely to be threatened by nagging behavior than the students' negative face. This hypothesis was supported. The results of a t-test indicated the student's positive face was more likely to be threatened by nagging than the students' negative face, $t(186)=13.44, p<.001$.

The seventh research question asked whether the politeness strategy used when committing the FTA would be associated with the nagging strategy reported. This research question was tested using a multivariate analysis of variance (MANOVA) with four dependent variables: bald on record, positive politeness, negative politeness, and offrecord strategies. The results from the MANOVA indicated there were significant differences in type of face threat used dependent on the nagging strategy, Wilks's $\Lambda=$ $.53, F(4,184)=5.12, p<.001$. A series of four ANOVAs were then conducted to determine the independent contributions of the dependent variables.

The results of the first ANOVA were significant, $F(6,180)=3.74, p<.01$. A post hoc Scheffe test indicated FTAs that were committed bald on record were utilized significantly more with the elicit student support nag $(M=.78, S D=85)$ than the barrage instructor with requests nag $(M=.08, S D=.27)$. 
The results of the second ANOVA were significant, $F(6,180)=4.58, p<.001$. A post hoc Scheffe test indicated FTAs that were committed with positive politeness were utilized significantly more with the suggest instructor incompetence nag $(M=.71, S D=$ $.85)$ than the strike a deal nag $(M=.07, S D=.26)$ and the barrage instructor with requests nag.

The results of the third ANOVA were significant, $F(6,180)=5.76, p<.001$. A post hoc Scheffe test indicated FTAs that were committed with negative politeness were utilized significantly more with the elicit sympathy nag $(M=.28, S D=.45)$ than the suggest instructor incompetence nag $(M=.00, S D=.00)$, the demonstrate frustration with the instructor nag $(M=.00, S D=.00)$, the elicit student support nag $(M=.00, S D=$ $.00)$, the strike a deal nag $(M=.00, S D=.00)$, and the barrage instructor with requests $\operatorname{nag}(M=.04, S D=.19)$.

The results of the fourth ANOVA were significant, $F(6,180)=10.13, p<.001$. A post hoc Scheffe test indicated FTAs committed off-record were utilized significantly more with the demonstrate frustration with the instructor nag $(M=1.63, S D=1.01)$ than the suggest instructor incompetence nag $(M=.76, S D=.89)$, the elicit student support $\operatorname{nag}(M=.70, S D=.67)$, the elicit sympathy nag $(M=.63, S D=.61)$, and the flatter instructor nag $(M=.79, S D=.69)$. A post hoc Scheffe test indicated FTAs that were committed off-record were utilized significantly more with the strike a deal nag $(M=$ $1.39, S D=.88)$ than the elicit sympathy nag. The post hoc test also indicated the FTAs committed off-record were utilized significantly more with the barrage instructor with requests nag $(M=1.69, S D=.47)$ than the suggest instructor incompetence nag, the elicit 
student support nag, the elicit sympathy nag, and the flatter instructor nag. The results for this research question appear in Table 3.

Hypothesis three posited that nagging behavior would be positively related to persistence. This hypothesis was supported, $r=.15, p<.05$. Participants who reported more frequency of nagging use also reported a greater likelihood of using persistence.

Hypothesis four posited that nagging behaviors would be positively related to compliance gaining. This hypothesis was supported, $r=.34, p<.001$. Participants who reported more frequency of nagging use also reported a greater likelihood of using compliance-gaining strategies.

Hypotheses five posited that nagging behaviors would be positively related to student challenge behaviors. This hypothesis was supported, $r=.46, p<.001$. Participants who reported more frequency of nagging use also reported a greater likelihood of using challenge behaviors. 
Table 3

Strategies of Committing Face Threatening Acts as a Function of Student Nagging

Behavior

\begin{tabular}{|c|c|c|c|c|}
\hline \multicolumn{5}{|c|}{ Mean Score } \\
\hline & $\begin{array}{l}\text { Bald on } \\
\text { Record }\end{array}$ & $\begin{array}{l}\text { Positive } \\
\text { Politeness }\end{array}$ & $\begin{array}{l}\text { Negative } \\
\text { Politeness }\end{array}$ & $\begin{array}{l}\text { Off } \\
\text { Record }\end{array}$ \\
\hline $\begin{array}{l}\text { Suggest Instructor } \\
\text { Incompetence }\end{array}$ & $.57_{\mathrm{b}}$ & $.71_{\mathrm{bc}}$ & $.00_{\mathrm{a}}$ & $.76_{\mathrm{ab}}$ \\
\hline $\begin{array}{l}\text { Demonstrate } \\
\text { Frustration }\end{array}$ & $.48_{\mathrm{b}}$ & $.29_{b}$ & $.00_{\mathrm{a}}$ & $1.63_{\mathrm{c}}$ \\
\hline $\begin{array}{l}\text { Elicit Student } \\
\text { Support }\end{array}$ & $.78_{\mathrm{bc}}$ & $.41_{\mathrm{b}}$ & $.00_{\mathrm{a}}$ & $.70_{\mathrm{ab}}$ \\
\hline Strike a Deal & $.39_{b}$ & $.07_{\mathrm{ab}}$ & $.00_{\mathrm{a}}$ & $1.39 \mathrm{bc}$ \\
\hline $\begin{array}{l}\text { Barrage with } \\
\text { Requests }\end{array}$ & $.08_{\mathrm{ab}}$ & $.12_{\mathrm{ab}}$ & $.04_{a}$ & $1.69_{\mathrm{c}}$ \\
\hline Elicit Sympathy & $.20_{\mathrm{b}}$ & $.60_{\mathrm{b}}$ & $.28_{\mathrm{bc}}$ & $.63 \mathrm{a}$ \\
\hline $\begin{array}{l}\text { Flatter the } \\
\text { Instructor }\end{array}$ & $.32_{\mathrm{b}}$ & $.61_{b}$ & $.07_{\mathrm{ab}}$ & $.79_{\mathrm{ab}}$ \\
\hline$F$ & $3.74 *$ & $4.58 *$ & $5.76^{*}$ & $10.13^{*}$ \\
\hline
\end{tabular}

Note: Suggest instructor incompetence $=21$ participants. Demonstrate frustration $=27$

participants. Elicit student support $=27$ participants. Strike a deal $=28$ participants. Barrage with requests $=26$. Elicit sympathy $=30$. Flatter the instructor $=28$. Means not sharing subscripts along each column are significantly different from each other. $* p<.001$. 


\section{Study Three}

The eighth research question was asked to determine whether student and instructor perceptions of the frequency of nagging behavior differed. A series of independent-samples t-tests were conducted to answer this research question. Student and instructor perceptions significantly differed on three of the seven nagging strategies. Students and instructors significantly differ in their perceptions of how frequently students use the barrage instructor with requests nag, $t(360)=-3.76, p<.001$, with instructors $(M=3.15)$ perceiving this nag to occur more frequently than students $(M=$ 2.40). Students and instructors significantly differ in their perceptions of how frequently students use the flatter instructor nag, $t(360)=-4.49, p<.0001$, with instructors $(M=$ 3.77) perceiving this nag to occur more frequently than students $(M=2.76)$. Students and instructors significantly differ in their perceptions of how frequently students use the elicit sympathy nag, $t(360)=-8.72, p<.0001$, with instructors $(M=4.88)$ perceiving this nag to occur more frequently than students $(M=3.08)$. None of the other independentsamples t-tests were significant: suggest instructor incompetence, $t(359)=-1.79, p>.05$; elicit student support, $t(360)=.42, p>.05 ;$ strike a deal, $t(360)=-1.43, p>.05$; demonstrate frustration with the instructor, $t(360)=-.91, p>.05$. The means for this research question, and research questions eleven and twelve, are presented in Table 4.

Research questions nine and ten were tested using a multivariate analysis of variance (MANOVA) with the seven nagging strategies serving as the dependent variables. The results from the MANOVA indicated there were significant differences in the perceptions of effectiveness and appropriateness dependent on the nagging strategy, 
Wilks's $\Lambda=.85, F(2,70)=952.15, p<.0001$. Two separate ANOVAs were then conducted to determine the independent contributions of each variable.

The ninth research question was asked to determine which strategy instructors perceived as the most effective. The results of an ANOVA were significant $F(6,75)=$ $11.99, p<.0001$. A post hoc Scheffe test indicated the elicit sympathy nag $(M=2.80)$ was perceived by instructors to be significantly more effective than the suggest instructor incompetence nag $(M=1.62)$, the strike a deal nag $(M=2.04)$, the barrage instructor with requests nag $(M=1.89)$, the demonstrate frustration with the instructor nag $(M=$ 1.37), and the flatter instructor nag $(M=2.07)$. A post hoc Scheffe test indicated the elicit student support nag $(M=2.22)$ was perceived by instructors to be significantly more effective than the suggest instructor incompetence nag, the barrage instructor with requests nag, and the demonstrate frustration with the instructor nag. A post hoc Scheffe test indicated the elicit student support nag and the flatter instructor nag were perceived by instructors to be significantly more effective than the demonstrate frustration with the instructor nag.

The tenth research question was asked to determine which strategy instructors perceived as the more appropriate. The results of an ANOVA were significant, $F(6,75)$ $=13.35, p<.0001$. A post hoc Scheffe test indicated the elicit sympathy nag $(M=2.52)$ was perceived by instructors to be significantly more appropriate than the suggest instructor incompetence nag $(M=1.39)$, the strike a deal nag $(M=1.68)$, the barrage instructor with requests nag $(M=1.60)$, the demonstrate frustration with the instructor nag $(M=1.10)$, and the flatter instructor nag $(M=1.74)$. A post hoc Scheffe test indicated the elicit student support nag $(M=1.93)$ and the flatter instructor nag were 
perceived by instructors to be significantly more appropriate than the demonstrate frustration with the instructor nag.

The eleventh research question was asked to determine whether student and instructor perceptions of the effectiveness of nagging behavior differed. A series of independent-samples t-tests were conducted to answer this research question. Student and instructor perceptions significantly differed for all seven nagging strategies. Students and instructors significantly differ in their perceptions of the effectiveness of the suggest instructor incompetence nag, $t(359)=6.79, p<.0001$, with students $(M=2.75)$ perceiving this nag to be more effective than instructors $(M=1.62)$. Students and instructors significantly differ in their perceptions of the effectiveness of the elicit student support nag, $t(359)=5.67, p<.0001$, with students $(M=3.45)$ perceiving this nag to be more effective than instructors $(M=2.23)$. Students and instructors significantly differ in their perceptions of the effectiveness of the strike a deal nag, $t(358)=5.34, p<.0001$, with students $(M=3.13)$ perceiving this nag to be more effective than instructors $(M=$ 2.04). Students and instructors significantly differ in their perceptions of the effectiveness of the barrage instructor with requests nag, $t(359)=5.07, p<.0001$, with students $(M=$ 2.84) perceiving this nag to be more effective than instructors $(M=1.89)$. Students and instructors significantly differ in their perceptions of the effectiveness of the demonstrate frustration with the instructor nag, $t(359)=4.89, p<.0001$, with students $(M=2.20)$ perceiving this nag to be more effective than instructors $(M=1.37)$. Students and instructors significantly differ in their perceptions of the effectiveness of the flatter instructor nag, $t(359)=6.58, p<.0001$, with students $(M=3.48)$ perceiving this nag to be more effective than instructors $(M=2.07)$. Students and instructors significantly differ 
in their perceptions of the effectiveness of the elicit sympathy nag, $t(360)=3.73, p<$ .0001 , with students $(M=3.58)$ perceiving this nag to be more effective than instructors $(M=2.80)$.

The twelfth research question was asked to determine whether student and instructor perceptions of the appropriateness of nagging behavior differed. A series of independent-samples t-tests were conducted to answer this research question. Student and instructor perceptions significantly differed for all seven nagging strategies. Students and instructors significantly differ in their perceptions of the appropriateness of the suggest instructor incompetence nag, $t(358)=5.58, p<.0001$, with students $(M=2.25)$ perceiving this nag to be more appropriate than instructors $(M=1.39)$. Students and instructors significantly differ in their perceptions of the appropriateness of the elicit student support nag, $t(359)=4.42, p<.0001$, with students $(M=2.79)$ perceiving this nag to be more appropriate than instructors $(M=1.91)$. Students and instructors significantly differ in their perceptions of the appropriateness of the strike a deal nag, $t$ $(360)=5.19, p<.0001$, with students $(M=2.79)$ perceiving this nag to be more appropriate than instructors $(M=1.74)$. Students and instructors significantly differ in their perceptions of the appropriateness of the barrage instructor with requests nag, $t$ $(360)=4.52, p<.0001$, with students $(M=2.53)$ perceiving this nag to be more appropriate than instructors $(M=1.68)$. Students and instructors significantly differ in their perceptions of the appropriateness of the demonstrate frustration with the instructor nag, $t(360)=5.71, p<.0001$, with students $(M=1.96)$ perceiving this nag to be more appropriate than instructors $(M=1.10)$. Students and instructors significantly differ in their perceptions of the appropriateness of the flatter instructor nag, $t(360)=5.84, p<$ 
.0001 , with students $(M=2.75)$ perceiving this nag to be more appropriate than instructors $(M=1.60)$. Students and instructors significantly differ in their perceptions of the appropriateness of the elicit sympathy nag, $t(360)=3.22, p<.0001$, with students $(M$ $=3.19)$ perceiving this nag to be more appropriate than instructors $(M=2.52)$. 
Table 4

Student and Instructor Mean Scores for the Frequency, Effectiveness, and Appropriateness of Nagging Strategies

Student Perceptions

Frequency Effective Appropriate Frequency Effective Appropriate

\begin{tabular}{|c|c|c|c|c|c|c|}
\hline $\begin{array}{l}\text { Suggest Instructor } \\
\text { Incompetence }\end{array}$ & 2.17 & 2.75 & 2.25 & 2.45 & 1.62 & 1.40 \\
\hline $\begin{array}{l}\text { Demonstrate } \\
\text { Frustration }\end{array}$ & 2.25 & 2.20 & 1.96 & 2.46 & 1.38 & 1.10 \\
\hline $\begin{array}{l}\text { Elicit Student } \\
\text { Support }\end{array}$ & 2.35 & 3.45 & 2.79 & 2.29 & 2.25 & 1.94 \\
\hline Strike a Deal & 2.81 & 3.13 & 2.79 & 3.11 & 2.03 & 1.75 \\
\hline $\begin{array}{l}\text { Barrage with } \\
\text { Requests }\end{array}$ & 2.40 & 2.84 & 2.53 & 3.13 & 1.89 & 1.70 \\
\hline Elicit Sympathy & 3.08 & 3.58 & 3.19 & 4.89 & 2.81 & 2.56 \\
\hline $\begin{array}{l}\text { Flatter the } \\
\text { Instructor }\end{array}$ & 2.76 & 3.48 & 2.75 & 3.79 & 2.09 & 1.60 \\
\hline
\end{tabular}

$\overline{\text { Note. Frequency was assessed with one item rated with responses ranging from (1) never }}$ to (7) always. Effectiveness was assessed with one item rated with responses ranging from (1) never effective to (7) always effective. Appropriateness was assessed with one item rated with responses ranging from (1) never appropriate to (7) always appropriate. 


\section{Summary}

The purpose of this section was to provide the qualitative and statistical results of studies one, two, and three. Through focus group discussions, the typology developed by Dunleavy and Myers (2006) was validated, and students provided reasons for their nagging behavior. Through coding of open-ended responses, nagging was examined with concepts from Politeness Theory. Using a summative measure of the frequency of nagging behavior, nagging was correlated with persistence, compliance gaining, and challenge behaviors. Using items that assessed the frequency, effectiveness, and appropriateness of nagging, the perceptions of students and instructors were compared. The following section will elaborate on these findings, discuss the limitations, and present possible future research of nagging behavior. 


\section{Chapter IV}

Discussion

The purpose of this dissertation was to explore a relatively new concept in instructional communication, student nagging behavior. As such, the intent of the studies conducted within the dissertation was to establish nagging as a construct separate from other related constructs and to validate the strategies students use to nag. A preliminary investigation of the perceptions of instructors was also conducted. The examination of Politeness Theory in association with nagging indicated the damage nagging could inflict on the face of both the nagger and the naggee. As a whole, the results of this dissertation indicate (a) there are seven student nagging strategies (suggest instructor incompetence, demonstrate frustrations with the instructor, elicit student support, strike a deal, barrage instructor with requests, flatter instructor, and elicit sympathy); (b) there are four major reasons why students nag instructors (instructor-related, education-related, affect-related, and preference-related); (c) nagging is positively related to other persuasive constructs; (d) nagging harms the positive and negative face of both students and instructors; and (e) student and instructor perceptions of nagging behavior significantly differ.

The first research question was asked in order to validate the strategies included in the typology developed by Dunleavy and Myers (2006). Coding of open-ended responses was used to develop the typology, and no inter-coder reliability was established in the original study. To ensure the results of that study and the consequent typology were not spurious, triangulation was necessary for validation (Frey, Botan, \& Kreps, 2000). To validate the typology in this study, a different method was utilized (i.e., focus groups), and inter-coder reliability was established with three coders. 
The results of the present study support the typology, with the exception of the challenge instructor authority nag which was subsumed under the suggest instructor incompetence nag. The problems with the challenge instructor authority nag begin with the description of the nag, which suggests it may be aggressive in nature. According to Soule (2001), nagging is characterized more by repetition than aggression, and this finding was integrated into the conceptualization of nagging behavior used in the dissertation. Persistent persuasion which is aggressive, or escalates to aggression, is not labeled as nagging. Not all discussions of the challenge instructor authority nag revolved around examples of physical and verbal aggression, but there were aggressive responses. Even with the inclusion of aggressive responses, there was a paucity of discussion about the challenge instructor authority nag. The lack of discussion indicated the strategy may not be utilized by students or possibly used as a nagging behavior at all.

Two non-aggressive descriptions of the nag that were included under the description of the suggest instructor incompetence nag were refusing to do work consistently in class and talking during lecture. Participants explained these behaviors were used when instructors were unclear, unhelpful, or hard to understand in the classroom. In a sense, these students gave up trying to learn and blamed the instructor for their inability to focus. Although the participants thought they were providing examples of the challenge instructor authority nag, in actuality they were indicating the instructor was not properly carrying out duties as a teacher. These examples are better suited under the suggest instructor incompetence nag, and were included there in the subsequent typology and studies. The conceptual issues and response issues did not afflict any of the 
other strategies and for this reason none of the other strategies were removed from the typology.

The second research question was asked to understand why students nag their instructors. If nagging is commonly thought of as an annoying behavior (Tannen, 1990), why would a student consciously choose to use this behavior in an exchange with an instructor? On the surface, there appears to be obvious answers to this question, but again the reasons for nagging are different than the intended outcomes of nagging. The intended outcomes that students reported included: extra points, grade curves, early dismissal, make up exams, and acceptance of late assignments. The intended outcomes are different than reasons for nagging, which provide insight into the decision-making process of the student to nag instructors. Soule (2006) also felt it was important to differentiate between the reasons and outcomes of nagging.

Soule (2006) posited two explanations for why individuals nag. First, individuals nag to show their affection and concern for the target of the nag. This clearly reiterates the affect-related category found in study one. Individuals use their nagging to demonstrate affection for someone. In order to develop and maintain relationships, some students nag their instructors. Participants in the study emphasized that this was particularly useful in large lecture classrooms where it was unlikely a close relationship would ever develop between student and instructor. However, participants also indicated this was useful in smaller classrooms and even in high school.

The explanation provided by Soule (2001) also overlaps the education-related category. According to Soule, nagging in marital relationships is used to show concern for one's spouse. Nagging about health issues such as smoking, dieting, and exercising 
demonstrates that a marital partner is concerned about the welfare of the spouse. These types of issues are less likely to be a factor in the classroom, and yet concern can still be demonstrated through nagging. In the classroom, students can demonstrate their concern for a grade, for the subject material, or for their future in the field. While these issues are not especially similar to the issues discussed by Soule (2001), there is parallel reasoning for why individuals nag in both of these contexts.

Soule (2001) provided a second explanation for why individuals choose to nag. This explanation involves a desire to avoid conflict and, if possible, to avoid the use of hurtful messages. Once again, there are similarities between this explanation and the categories that emerged in the first study. This explanation overlaps the preferencerelated reason for nagging. Students attribute their nagging to a decision to avoid the use of more aggressive strategies. Even at the end of the semester, students recognize that their paths may cross with instructors in the future. One participant briefly mentioned the instructor's ability to "control your fate." Nagging is therefore a subtle strategy that prevents the student from using aggression or saying something that might harm the instructor's perception of the student.

The two explanations for why individuals nag were not empirically tested and these explanations were intended to explain nagging in marital relationships (Soule, 2001). However, similarities exist between these explanations and the reasons found in study one. The similarities suggest these reasons are explanations for student nagging behavior.

The final category of reasons for nagging behavior was instructor-related. Students attribute their nagging to the instructor because the instructor is not responsive 
or the instructor encourages the nagging. This category is important because it reiterates the point made by Kozloff (1988) that nagging behavior is the result (or fault) of both the nagger and the naggee. Although students are making a conscious decision to nag, this behavior can also be attributed to the actions of instructors. Soule (2001) also found nagging to be the product of the two individuals in the marriage. Nagging could not be attributed only to the nagger in the relationship. While the effects of nagging have yet to be fully examined, future research should remain focused on both the student and the instructor behaviors. These instructor-related reasons indicate that some nagging behavior is the product of two people and not the individual decision of the nagger.

Study two served two purposes; the first purpose, similar to study one, was to provide validity to nagging. However, in this study the validity was established for nagging as a construct, not the nagging strategies. In chapter one, constructs related to nagging behavior were compared and contrasted. This was then examined in study two to ensure there actually was a commonality between these constructs. It was also important to demonstrate the relationship between these constructs was not to the extent that they were measuring the same behaviors.

A measurement of nagging behavior was created from the strategies in the modified typology. Typically, these strategies would be examined singularly, much like the behaviors included in the typology of the behavior alternation techniques (BATs) or the typology of student misbehaviors (Kearney, et al., 1988; Plax, et al., 1986). To assess nagging behavior the typology was measured as a summative scale, which is a technique also used with the BATs typology. Participants indicated how frequently they used each 
nagging strategy. Participants with higher scores on the summative scale would be those individuals who would be considered naggers.

It was posited in hypothesis one that these individuals would also be more likely to use persistence, a concept used to describe nagging (Kozloff, 1988; Soule, 2001, 2006). It was posited in hypothesis two that these individuals would also be more likely to use more compliance-gaining strategies, another persuasive construct (Hunter \& Boster, 1987). Finally, it was posited in hypothesis three that these student participants would also be more likely to use challenge behavior with instructors, a classroom construct associated with unexpected student behavior (Simonds, 1997).

While all three hypotheses were significant, the correlations are small or moderate, between .15 and .46 . Nagging is positively related to persistence, compliance gaining, and challenge behavior, but these each remain separate constructs. Chapter one discussed how nagging was similar, but still different from persistence, compliance gaining, and challenge behaviors. The results from study two support this argument; there are similarities between the constructs, but there are differences as well.

The strongest correlation was found between nagging and student challenge behaviors. Neither construct is assumed to be negative; nagging can be used constructively to remind an instructor of something, and challenge behaviors can ensure an instructor changes dated classroom procedures (Simonds, 1997). However, both of these constructs can possibly produce negative outcomes.

A problem to recognize when considering the relationships found between these constructs is the low reliability of the nagging frequency measure. A factor analysis of the seven nagging strategies failed to show any underlying dimensions. It was thought 
individuals who frequently nag would utilize numerous nagging strategies and that by summing one's nagging strategy scores one would have an overall nagging measure. However, the results here indicate it is probable that a person could utilize one particular nag with high frequency and not another. It is also possible that people differ in the strategies that they utilize due to differences in traits, or due to contextual or situational factors. These factors were not taken into account in the present study but could be reasons for the low reliability. It should be noted that the purpose of this study was not to establish a measurement of nagging. The purpose was to define and investigate the nagging construct. Although reliability for a measure of nagging frequency was low, relationships were established between nagging and persistence, compliance gaining, and challenge behaviors.

Research questions three and four were asked to examine the FTAs of nagging on instructors. The flatter instructor nag was more threatening to instructors' negative face than the strike a deal nag or the elicit sympathy nag. Although not significantly different, the flatter instructor nag was more threatening to the instructors' negative face than the suggest instructor incompetence nag, the demonstrate frustration with the instructor nag, the elicit student support nag, and the barrage the instructor with requests nag. Based on the means, it appears that the flatter instructor nag is the most threatening to the instructors' negative face.

While all nagging strategies are characterized by persistence, the flatter instructor nag is considered, by students, to be a long term commitment. Students believe this nag must be used early in the semester and must continue to be used in order to be effective (Dunleavy \& Myers, 2006). According to a female student who participated in study one, 
an instructor will see through this nag right away if it is used only when the student needs something. This student commented, "If somebody comes up to [the instructor] and is being kind of flirtatious or, you know, laughing... sometimes you can even see it on the instructor's face they're like, 'who are you?'" The implication of statements like this is that an instructor's time is going to be spent as a student nags with the flattering strategy. The instructors' negative face is threatened by this type of nag because it must be used throughout the semester in order to be effective.

During the focus group discussions of this nag, students indicated this particular nag did not often occur during class time. The student often needed to approach the instructor in the office or, even more commonly, out in public. The instructors' time is encroached not only in the workplace, but also in their private lives. Although this nag is intended to be complimentary, it does require the instructor to take personal time, and the negative face of instructors is more threatened by this strategy than any other.

Research question four examined the positive face threats of nagging on instructors. The suggest instructor incompetence nag and the demonstrate frustration with the instructor nag were significantly more face threatening than any of the other five nags. Although not significantly different, the demonstrate frustration with the instructor nag was more threatening to the instructors' positive face than the suggest instructor incompetence nag. Based on the means, it appears that the demonstrate frustration with the instructor nag is the most threatening to instructors' positive face.

The significant difference between the suggest instructor incompetence nag and the demonstrate frustration with the instructor nag and other opposing strategies, such as the flatter instructor nag, is unsurprising. Whereas the first two strategies are intended to 
highlight unfavorable qualities of the instructor, the flatter instructor nag is intended to compliment the instructor and promote favorable qualities. Based on the descriptions of these nags, the suggest instructor incompetence nag and the demonstrate frustration with the instructor nag are intended to threaten the positive face of instructors. Participant descriptions of interactions in which these strategies are used are then significantly more likely to provide examples of positive face threats than other strategies that are not described in this way.

Other nags, such as the elicit sympathy nag, do not oppose the suggest instructor incompetence nag or the demonstrate frustration with the instructor nag, but they do not have as much to do with the instructor either. The elicit sympathy nag is a strategy in which the student is self-disclosing, it is not a strategy in which the student refers to instructor behavior either positively or negatively. Because this strategy has little to do with instructor behavior, the possibility to threaten instructors' positive face is limited. The suggest instructor incompetence nag and the demonstrate frustration with the instructor nag are significantly different from the other strategies because the other strategies are not characterized with negativity towards the instructor, nor do they have to do with instructor behavior.

The two most face threatening nags are marked by criticisms of the instructor, with the suggest instructor incompetence employing more verbal behaviors and the demonstrate frustration with the instructor employing more nonverbal behaviors. The nonverbal behaviors appear to be more threatening to instructors' desire to be liked and respected. According to participants in study one, this is because the students feel more comfortable expressing negative messages nonverbally. A female student commented, "If 
you were to put those behaviors into words you're pretty much saying, 'ok, let's go. Hurry up. I have better things to do."” A male student also commented, "Nonverbally, more people are going to do it too. If it's verbal no one's gonna-except for the crazy kid in the class. There's not going to be anyone who just stands up there and says, 'We need to leave now."' The statements above indicate that students realize how critical they can be of instructors and how much more comfortable students are with delivering a negative message nonverbally. The implication is that the students would not verbalize the "translation" of their nonverbal messages. Although the verbal messages have just as much potential to be threatening to instructors' positive face, students choose to express these messages nonverbally, which is one reason why the demonstrate frustration with the instructor nag is more threatening to the instructors' positive face than the suggest instructor incompetence nag.

Research questions five and six were asked to examine the FTAs of nagging on students. The strike a deal nag was significantly more threatening to the negative face of students than the suggest instructor incompetence nag, the demonstrate frustration with the instructor nag, and the flatter instructor nag. Although not significantly different, the strike a deal nag was more threatening to the student's negative face than the elicit student support nag, the barrage instructor with requests nag, and the elicit sympathy nag. Based on the means, it appears that the strike a deal nag is the most threatening to students' negative face.

The strike a deal nag requires substantial time for the student to both initiate and execute. The student must spend time, often outside of class, to establish the bargain that is made. The students' time taken to negotiate grades has been established in a previous 
study. Sabee and Wilson (2005) found students threatened their own negative face more often when persuading instructors to change grades than when they attempted to learn more, to impress the instructor, or to fight with the instructor about a disappointing grade. Although all of the reasons for meeting with the instructor involved a disappointing grade, it was the negotiation of the grade that threatened the students' negative face the most.

The threat to the students' negative face was also noted in study one. Participants in study one remarked that these negotiations take time and that several attempts must often be made before the deal is struck. According to one male student, "I usually go with the big offer and then, maybe, get narrowed down to something...less." The initiation of the deal requires the time of the student, which is why this nag is more face threatening than the other strategies. However, when nagging the instructor, students implicate themselves into a further time commitment. By making deals, the student often has to produce extra work, or extra preparation, that will require more of the students' time outside of class. The time it takes to nag the instructor with this strategy, and the promise of spending extra time as part of the deal, presents strong reasoning for why this strategy would be more threatening to the students' negative face than the other strategies.

Research question six examined the positive face threats of nagging on students. The strike a deal nag and the elicit sympathy nag were significantly more threatening to students' positive face than the suggest instructor incompetence nag and the demonstrate frustration with the instructor nag. Nagging strategies such as suggest instructor incompetence, demonstrate frustration with the instructor, and flatter instructor are instructor centered. In the process of nagging with these strategies, the behavior of 
instructors is underscored, either negatively or positively. The strategies that are most likely to threaten students' positive face, the strike a deal nag and the elicit sympathy nag, are student centered. In the process of nagging with these two strategies, the behavior of the students themselves is underscored. Neither of these strategies are characterized by a direct criticism of the instructor. Therefore, if positive face is threatened, it is likely to be the face of the student. Any discussion of a student's progress in a course, and how it can be improved, is inherently face threatening to the positive face of the student (KerssenGriep, 2001; Kerssen-Griep, Hess, \& Tress, 2003). When students mention their own behavior in a course they are then inherently threatening their own positive face.

Although not significantly different, the elicit sympathy nag was more threatening to the student's negative face than the strike a deal nag. Based on the means, it appears that the elicit sympathy nag is the most threatening to students' positive face. The elicit sympathy nag is characterized by students providing personal excuses and explanations for their performance in the classroom. When using this strategy, students are selfdisclosing information about themselves that the instructor would not otherwise know. Some of this information may make the student look unfavorably. For example, a participant in study two described a time in which she had to provide her instructors with information about a "court related issue." Students are placed in a vulnerable position as they reveal this information, which could be damaging to their face.

Participants in study one indicated the information provided when using the elicit sympathy nag was often inaccurate. No participants expressed an opinion that the use of this strategy was completely sincere. One participant estimated that the proportion of honest disclosures to dishonest disclosures was "50/50." These opinions indicate the 
elicit sympathy nag can be used dishonestly. Students are also aware that instructors are not ignorant to this dishonesty. A female participant remarked, "I feel like teachers never believe you anyway even if you're telling the truth because so many people [lie] and everybody lies." The dishonesty may contribute to threat to the students' positive face, making this more face threatening to students than other strategies.

The first two hypotheses posited nagging behavior would be more threatening to the negative face of instructors and the positive face of students. The first hypothesis was not supported; the second hypothesis was supported. Nagging behavior appears to be more threatening to the positive face of the interactants than the negative face.

It was predicted that nagging would require more of the instructors' time, to listen to and to deal with, than it would harm the instructors' positive face, but this was not supported. Instead, nagging behavior is more threatening to students' perceptions of their instructors' desire to be liked and respected. When describing their nagging exchanges, participants in study two were straightforward about their attempts to nag the instructor while not taking care to maintain the positive face of the instructor. A female student described her experience nagging an instructor who she felt was too stringent when grading assignments. The student wrote, "One time [the instructor] pronounced the word 'muscle' as 'mucus' and I told her she didn't even know how to read, much less teach a class." When nagging to receive extra credit, a male student told the instructor how "worthless" the class was. To get what they wanted, these participants were not as careful of enhancing, or even maintaining, the positive face of their instructors. There were fewer instances in which students acknowledged they were taking up the instructors' time. 
The same was true for students' negative face. Students were less likely to threaten their own time by nagging than they were to threaten their desire to be perceived as intelligent and hard working. Students willingly acknowledged that, even after studying, they could not grasp material. Students admitted they had not studied adequately, that they were behind in other classes, and that they had not read the assigned material. Again, these are topics that focus on the students' need for improvement in the class, which is inherently threatening to the positive face of the student (Kerssen-Griep, 2001; Kerssen-Griep, et al., 2003). Although students made admissions, they did not as often volunteer to spend extra time catching up while nagging instructors. The admissions that threatened the positive face of students were more likely to occur while nagging than the suggestion that the students would spend personal time solving the problem.

Research seven was asked in order to examine the type of strategy used when committing an FTA while nagging. The most direct type of strategy is bald on record, in which an individual explicitly threatens the face of another. The elicit student support nag was committed bald on record significantly more than the barrage instructor with requests nag. Although not statistically significant, the elicit student support nag was committed with a bald on record strategy more than any other nag.

Students report using the elicit student support nag with an issue that is large and that will affect the majority of the class. In study one, participants discussed having "strength in numbers" when using that nag. The extra assistance may create a sense of confidence in the nagging students who then nag more assuredly with the bald on record strategy. A participant in study two wrote about an exchange in which an instructor, who 
cancelled class several times in a row, then required students to take the exam at the regularly scheduled time. The class then nagged the instructor to change the date. According to the student, "I told her 'there is no way we can take this test, you never taught us this.' Other people said, 'we can't have a test [this day], it's not fair."' The students were explicit in what they thought was unjustified, and they were direct in placing the blame on the instructor. The explicit nature of bald on record may make this an unfavorable method for some students who instead choose to use the positive politeness, negative politeness, or off record strategies.

Committing a FTA with positive politeness means acknowledging the positive face of the interactants may be harmed while communicating. The suggest instructor incompetence nag was committed with positive politeness significantly more than the strike a deal nag. Although not significantly different, the suggest instructor incompetence nag was used with positive politeness more than any other nag. As previously mentioned, this nag is one of the more threatening to the instructors' positive face. Students may recognize the harm they could cause to the instructors' face and realize the threat is too extreme to try and downplay the effects with the innocuous off record strategy. Instead, students may realize they have to acknowledge the potential damage and try to curb these effects with the positive politeness strategy.

A male participant described a semester in which his instructor continuously used the wrong formulas when solving equations. The student repeatedly tried to indicate to the instructor that the formulas were wrong and that the instructor should complete the examples himself before class. On one occasion, the instructor asked the student to solve one of these formulas. The student quoted himself as saying, "I would love to show my 
work but I see the problem has a few things wrong with it," to the instructor. The student did not directly threaten the instructor's face, nor did the student commit the act off record. The student acknowledged there was an underlying criticism of the instructor, which is characteristic of the positive politeness strategy.

Committing an FTA with negative politeness means acknowledging the negative face of the interactants may be harmed while communicating. The elicit sympathy nag was committed with negative politeness significantly more than the suggest instructor incompetence nag, the demonstrate frustration with the instructor nag, the elicit student support nag, the strike a deal nag, and the barrage instructor with requests nag. Although not significantly different, the elicit sympathy nag was committed with negative politeness significantly more than the flatter instructor nag.

When eliciting sympathy from instructors, students often threatened their own negative face. Students referred to the time commitment they would have to make in their personal lives while eliciting sympathy from their instructors. A participant in study two with a large work load nagged a professor for an extension during midterms. The student commented, "I explained that I felt I could do better work/learn more from the project if I had more time." The student was trying to elicit sympathy from the instructor, but in so doing was referring to the extra time she would spend on work for the instructor's class. The student was acknowledging the threat to her own negative face, which may have contributed to her attempt to elicit sympathy from the instructor. Students also acknowledged the threat to the instructor's negative face while using the elicit sympathy nag. When asking for a makeup exam, students admitted it would take more of the instructor's time to write another exam. Although this was not always the case when the 
negative face was threatened, students using the elicit sympathy nag often confessed the time constraints required by their nag.

Committing an FTA off record is the least direct and the least damaging way of threatening the face of the interactants while communicating. The demonstrate frustration with the instructor nag and the barrage instructor with requests nag were committed off record significantly more than the suggest instructor incompetence nag, the elicit student support nag, the elicit sympathy nag, and the flatter instructor nag. Although not significantly different, the barrage instructor with requests nag is committed off record more than the demonstrate frustration with the instructor nag. The use of the demonstrate frustration with the instructor nag has the potential for positive face threat of the instructor. According to Brown and Levinson (1987), speakers increase the politeness of a message as the potential for threat increases in a message. Supporting this statement, students may commit the demonstrate frustration with the instructor nag off record so as to limit the threat of the nag.

Students use several channels to nag the instructor when using the barrage instructor with requests nag, but they were not direct or explicit when committing a FTA. A participant in study two described an interaction in which he had an instructor who was very "unclear" in class. The student felt his grade was affected by the inability of the instructor to clearly relay the material, however the student did not express this when nagging the instructor. Instead, the student sent several emails and approached the instructor after class and asked questions about content. The student never directly criticized the instructor when nagging for clarification. Students may feel this nagging strategy is obvious to begin with and do not feel the additional face threat will help their 
case. In study one, participants reported using the barrage instructor with requests nag, but they described the strategy as "annoying." Others said the nag demonstrated their “determination." Regardless of the positive or negative effects of being annoying or determined, the behavior is difficult to ignore. Students may choose to use a straightforward strategy (i.e., barrage instructor with requests) but balance the effects of the strategy by the avoidance of a direct face threat. Students using this nag choose more often to commit face threatening acts off record.

It should be noted that the majority of all FTAs while nagging were committed off record. Committing an FTA is the most innocuous, possibly ambiguous, strategy. Students favor this strategy over the other three, no matter which nagging strategy is utilized. This result is similar to the preference related reason for choosing to nag, which was found in study one. Students prefer to use nagging to get what they want because they find it a subtle strategy. It is possible that this is the same reason students choose to commit FTAs off record.

It is also possible that students commit FTAs off record because of the power differential in the teacher-student relationship. Even in small classrooms, the relationship between students and their instructors lack equality (Frymier \& Houser, 2000). Students have considerably less power than instructors in the classroom. Recognizing this, students may understand that attempting to more directly threaten the instructor will not be effective. Direct threats also have the potential for more negative effects, which students may want to avoid, again because of the power differential. Students who use compliance-gaining strategies with instructors tend to limit the use of negative strategies, if they use negative strategies at all (Golish, 1999). Students use nagging, which they 
deem a subtle persuasive tactic, and apparently try to reduce the threat of more forceful nags (e.g. the suggest instructor incompetence nag, and the demonstrate frustration with the instructor nag) with an off record strategy.

Overall, nagging is inherently face threatening. Nagging can threaten the positive and negative face of instructors, although nagging is more damaging to the instructors' positive face. Nagging can also threaten the positive and negative face of the students who nag. Again, nagging is more damaging to the students' positive face. While nagging poses potential for threat for the interactants, the threat can be reduced when committed off record. Certain strategies, such as the flatter instructor, are committed bald on record more than other strategies; however, most all nags are committed off record. The threat for face damage is inherent when using nagging behavior, but students who nag attempt to curb the potential for threat by committing the threat off record.

The purpose of the third study was to ascertain the instructors' perception of student nagging behavior, as compared to the students' perception. Dunleavy and Myers (2006) examined the students' perception of the frequency, effectiveness, and appropriateness of student nagging behavior. The third study examined this again with the modified typology and compared the perceptions of the students with the perceptions of the instructors.

Research question eight was asked to determine whether student and instructor perceptions nagging frequency differed. The perceptions did not significantly differ for four of the nagging strategies: suggest instructor incompetence, elicit student support, strike a deal, and demonstrate frustration with the instructor. Students and instructors are fairly equivalent in their perception of how often certain student nagging strategies are 
used, just as students and instructors are fairly equivalent in their perception of how often certain power bases are used by instructors (McCroskey \& Richmond, 1983). While students have several instructors a semester and instructors have many students a semester, both groups can generally discern how often certain behaviors occur.

Where students and instructors differed was the perception of the barrage instructor with requests nag, the flatter instructor nag, and the elicit sympathy nag. For these three nags, instructors believed nagging to occur with significantly greater frequency than students. From study two, the flatter instructor nag was found to be the most threatening to the instructors' negative face. When students use this strategy instructors may realize the time it will require listening and responding to this form of nagging. For this reason, the nag may appear to occur with more frequency to instructors who are attempting to protect their negative face.

The barrage instructor with requests nag is unique in that the nagging can occur through several channels simultaneously. An instructor arriving to the office may find phone messages, emails, and a handwritten note all from the same student with the same request. The simultaneous use of several channels is different than the use of suggesting instructor incompetence, or demonstrating frustration with the instructor, after class over several different days. When students flood the instructors available channels of communication this may influence the instructors' perception of how often this nagging strategy occurs.

It is also possible that more students are actually using the barrage instructor with requests nag as opposed to other strategies which may require the student to enact the behavior face-to-face, such as the demonstrate frustration with the instructor nag. 
Reticent students, or those who try to avoid communication in order to avoid looking foolish, prefer to communicate with instructors using asynchronous communication channels, such as email (Kelly, Keaten, \& Finch, 2004). The barrage instructor with requests nag allows reticent students the opportunity nag, which they might not find possible with any other nagging strategy. As personal factors such as reticence were not accounted for in the present study, this reasoning can only be proposed, not supported.

Why do instructors perceive the barrage instructors with requests nag, the flatter instructor nag, and the elicit sympathy nag to occur more frequently than students? Students do not perceive this nag, and two other nags, to occur with as much frequency as instructors. Two possible explanations for this are proposed. First, the nature of the nagging may influence the instructors' perception to assume the nag occurs with more frequency. Second, the nag may actually occur with more frequency than students realize because they do not see some of these behaviors enacted by students because they occur outside of the classroom.

Research questions nine and ten were asked to determine which nagging strategies instructors find the most effective and appropriate, respectively. The elicit sympathy nag was perceived to be significantly more effective than the suggest instructor incompetence nag, the strike a deal nag, the barrage instructor with requests nag, the demonstrate frustration with the instructor nag, and the flatter instructor nag. Although not significantly different, instructors reported the elicit sympathy nag to be more effective than the elicit student support nag.

Students perceived the elicit sympathy nag to be the most effective nag in a previous study (Dunleavy \& Myers, 2006). This may be perceived as the most effective 
because the excuses provided are often something the instructor can identify with. A participant in study one commented, "Professors can, like...can feel kind of like...they've been in a situation like that too before. Even if you go tell them, 'you know how it feels to have a death in the family.' 'You know how it feels to be sick and not be able to do anything." The implication is that the instructor can identify with the problem and will acquiesce to the request because of this identification. This strategy also involves a subjective quality that students believe instructors have difficulty disagreeing with. A student can elicit sympathy by describing how badly they feel to an instructor. The instructor will have a hard time disputing the emotions of the student, and this results in the instructor complying. For instance, a female participant from study one described an instance in which she told an instructor she was upset about something. According to the student, "You're never really right or wrong about...like, they can't be like, 'no, you're not upset." Instructors did not participate in focus groups in any of these studies, but the explanations provided by students can aid in understanding why instructors may find the elicit sympathy nag the most effective. The excuses used when eliciting sympathy are easy to identify with, and the excuses can also be difficult to dispute.

Research question ten was asked to determine which strategy instructors find the most appropriate. The elicit sympathy nag was perceived to be a significantly more appropriate strategy to employ than the suggest instructor incompetence nag, the strike a deal nag, the barrage instructor with requests nag, the demonstrate frustration with instructor nag, and the flatter instructor nag. Although not significantly different, the elicit sympathy nag was perceived to be more appropriate than the elicit student support 
nag. Students also perceived the elicit sympathy nag to be the most appropriate nag in a previous study (Dunleavy \& Myers, 2006).

Instructors initially may perceive this nag to be more appropriate than nags such as the suggest instructor incompetence nag, or the demonstrate frustration with the instructor nag, which threaten the positive face of the instructor. Instructors may also perceive this nag to be more appropriate than a nag such as the flatter instructor nag, which threatens the negative face of the instructor. Any nag which can cause damage the instructors' face is not likely to be perceived as appropriate to use.

The elicit sympathy nag may also be perceived as the most appropriate by instructors because of the self-disclosure necessary to enact the nag. Students must provide personal information to the instructor in order to use this nagging strategy. The usefulness of the student providing personal information is twofold. First, the selfdisclosure can help the instructor-student relationship develop (Taylor \& Altman, 1973), which is necessary if higher levels of learning are to occur (Frymier \& Houser, 2000). Second, students who are more involved in communication with their instructors are perceived as more effective communicators (Frymier, 2005). Even if the self-disclosure does not involve classroom topics, it can open the lines of communication between the student and instructor and can demonstrate the interest the student has in keeping up with the class.

Research questions eleven and twelve were asked to determine whether student and instructor perceptions of nagging effectiveness and appropriateness differed. Student and instructor perceptions were examined for each nagging strategy. Students and instructors significantly differed in their perceptions of the effectiveness and 
appropriateness of every single nagging strategy, with students finding every nagging strategy significantly more effective and appropriate than instructors. It is interesting to find that students and instructors have similar perceptions of the frequency at which nagging occurs for the majority of the strategies, but students find nagging to be more effective and appropriate than instructors.

The difference in perceptions of effectiveness could have to do with the social desirability bias of the instructor sample. Instructors may not want to acknowledge how much they acquiesce to student nagging. Not all instructors comply with nagging to the extent that they promote it, although participants in study one did cite examples of instructors who encouraged nagging behavior. However, this doesn't mean that instructors do not find nagging behavior effective. Even instructors who find the behavior annoying and childish may acquiesce because the nagging exhausts them and they want it to stop. Although the nagging will stop in the short term, complying actually reinforces the behavior and the student is then more likely to attempt nagging that instructor in the future (Kozloff, 1988). According to a participant in study one, "I feel like if you nag, then they know you. If you have that problem again they're gonna say, 'Well this kid is going to come after me so I better take care of it now so that it doesn't happen again."” Instructors may not want to admit the extent that nagging behavior is effective at changing their behavior with some students.

The difference in perceptions of appropriateness could have to do with the desire of the student sample to view their behaviors as acceptable. Cognitive Dissonance Theory may be useful in explaining this result. The premise of Cognitive Dissonance Theory is that inconsistencies in thought motivate an individual to change (Festinger, 1957). A 
student who uses nagging strategies, but believes the behavior to be inappropriate, will experience dissonance. The student will be motivated to reduce this dissonance. One of the ways that the student can reduce the dissonance is to change the belief about the nagging behavior. Instead of perceiving the behavior as inappropriate, the student can change the perception so that at least some of the nagging strategies are believed to be appropriate. The dissonance is reduced, and the student is more comfortable with the behavior. Therefore, students may perceive nagging behavior to be more appropriate because this is behavior they enact. The discomfort experienced while enacting a behavior that is deemed inappropriate is reduced by believing the behavior to be more appropriate. The instructor is not experiencing dissonance because it is not the instructor's behavior that is being judged. Instructors are judging the behavior of another (the student) and, for this reason, may feel more comfortable determining the behavior to be less appropriate.

It should be noted that, overall, student and instructor perceptions of the frequency, effectiveness, and appropriateness of nagging are all below the average of the scale used to rate the perceptions. On a scale with a maximum score of seven, the average responses of both students and instructors were usually below four. It appears that students and instructors do not find nagging to be a common occurrence and, in general, do not find nagging to be particularly effective or appropriate. Nagging does occur frequently enough to be rated by students and instructors, and to the extent that students can readily discuss and provide examples of their own nagging behavior. 


\section{Limitations}

When interpreting the results of this dissertation two limitations should be noted. The first limitation involves the number of participants in studies two and three. Both of these studies had adequate participants to achieve results; however, more participants would have been desirable. In study two, the 189 participants were compared by the nagging strategy they chose to report. As a result of this, only one nagging strategy was reported on by at least 30 participants. While the number of participants was fairly consistent throughout the categories of nagging strategies, the results would have been strengthened with more participants reporting on each category.

The results in study three would also have been strengthened if the instructor sample was larger. Instructor participants can be difficult to obtain. In previous studies, the response rate of instructors was above 30\% (Roach, 1998). In this dissertation, the instructor response rate was slightly below $30 \%$. Fortunately, both the instructor and student samples were obtained from diverse departments. However, the rather large student sample compared to a small instructor sample remains problematic.

The second limitation involves the perceptions of nagging that were assessed in study three. Both participant samples were instructed to indicate how often they perceived student nagging behavior to occur. Although this direction was given, it is possible that some of the participants reported on their own nagging behavior (the student sample) or on the nagging behavior of their students (the instructor sample). It is supposed that one's own experiences with nagging will shape the perception of nagging in general, but it was asked that participants report on their perceptions, not personal experiences. It is unknown whether some participants did not follow directions and chose 
to report on experiences, which may have influenced the data. Two instructor participants sent emails inquiring about this issue. These participants were given further instructions, but it is not known whether other participants were also confused and did not attempt to clarify their confusion, or whether the other participants understood the directions. The confusion over the perceptions and experiences could have influenced the results of study three so that the participants were responding to different questions.

\section{Future Directions}

As student nagging behavior is a new area of interest, there are many options for future research. First, research can continue to explore the use of the nagging strategies. According to the definition, nagging involves persistence regarding the same content. This does not suggest that the nagger could not alternate strategies. Research should investigate whether students choose to utilize the same strategy repeatedly, such as the flatter instructor nag, or whether students advance their strategies after refusal. This could also be dependent on the reason for the nag. For instance, if the reason for nagging is instructor related, in which the instructor encourages the student to nag, the student may utilize the same type of nag repeatedly knowing the instructor advocates the nagging usage. If the reason is education related, in which the student is having difficulty understanding the material, the student vary the nagging strategies in hopes of being subtle and still gaining the needed knowledge. The relationship between the reason for nagging and the strategies implemented should be investigated.

Second, student traits associated with student nagging could be assessed. Soule (2001) did not consider nagging to be trait-like, however there may be reason to question this. Certain student nagging behaviors, such as the flatter instructor nag and the elicit 
student support nag, are perceived as effective, but are not considered appropriate by students. It was suggested by Dunleavy and Myers (2006) that there may be certain traits, such as Machiavellianism, that contribute to the usage of inappropriate traits. It is not clear whether nagging is trait-like, or if it is more dependent on the situation. Research should explore this and identify possible traits that are associated with nagging behavior.

Third, just as certain traits may be associated with students who nag, the student perceptions of the instructor may influence how often nagging is used. In study one, a reason for student nagging behavior was instructor related. Some students attribute their nagging behavior to particular instructors. A factor in dispelling student resistance and student misbehavior is the power of the instructor (Kearney \& Plax, 1992). Instructors can implement the appropriate BATs to resolve a disruptive situation. This may also play a role in the instructor diminishing the number of nags received. The student perception of instructor credibility may play a role in whether the student chooses to nag. Students use more resistance strategies with instructors they perceive to be immediate and open (Burroughs, et al., 1989). Therefore, it is possible that students use more nagging behaviors with instructors they perceive to be more caring (one dimension of credibility). The behaviors of instructors and the possible influence this has on nagging behavior should be examined.

Fourth, the effects of nagging in the classroom should be examined. Soule (2001) ascertained nagging was not always a negative behavior or resulting in damaging outcomes. This dissertation also took that stance, and nagging was not considered negative behavior. In the future, research should examine this further, in particular, exploring both the positive and negative effects of nagging behavior. The use of the elicit 
student support nag, for instance, could be useful in indicating to an instructor that there is confusion over course material. The use of the suggest instructor incompetence nag in classroom, may cause tension and harm the classroom climate. As one purpose of instructional communication is to provide instructors with pedagogical knowledge, research should contribute to this knowledge (Sprague, 1993). Understanding how student nagging behavior affects the classroom can lead to later studies which focus on how instructors can use this behavior to enhance student learning.

\section{Conclusion}

The purpose of this dissertation was to explore student nagging behavior. A definition of nagging was provided, as well as a corrected typology of student nagging behaviors. Arguments were presented for why nagging is different from related constructs, and this was supported by the results from study two. The inherent threat that nagging poses for students and instructors was established, as well as the strategies used to minimize or maximize that threat. Finally, the instructors' perception of nagging compared to the students' perceptions. While students and instructors are relatively matched in their perception of the frequency at which nagging occurs, students perceive nagging to be more effective and appropriate than instructors. Nagging is a behavior that occurs in the student-instructor relationship, and while this behavior can be damaging to the face of the interactants, more research is necessary to determine whether this behavior is damaging to the classroom climate. 


\section{References}

Alberts, J. K. (1988). An analysis of couples' conversational complaints. Communication Monographs, 55, 184-197.

Alicke, M. D., Braun, J. C., Glor, J. E., Klotz, M. L., Magee, J., Sederholm, H., \& Siegel, R. (1992). Complaining behavior in social interaction. Personality and Social Psychology Bulletin, 18, 286-295.

Baxter, L. A. (1984). An investigation of compliance gaining as politeness. Human Communication Research, 10, 427-456.

Boster, F. J., Kazoleas, D., Levine, T., Rogan, R. G., \& Kang, K. H. (1995). The impact of power on communicative persistence, strategic diversity and bargaining outcomes. Communication Reports, 8, 136-144.

Boster, F. J., \& Levine, T. (1988). Individual differences and compliance gaining message selection: The effects of verbal aggression, argumentativeness, dogmatism, and negativism. Communication Research Reports, 5, 114-119.

Boster, F. J., Mitchell, M. M., Lapinski, M. K., Cooper, H., Orrego, V. O., \& Reinke, R. (1999). The impact of guilt and type of compliance gaining message on compliance. Communication Monographs, 66, 168-177.

Brown, P., \& Levinson, S. C. (1987). Politeness: Some universals in language usage. Cambridge, UK: Cambridge University Press.

Burroughs, N. F., Kearney, P., \& Plax, T. G. (1989). Compliance resistance in the college classroom. Communication Education, 38, 214-229.

Caughlin, J. P. (2002). The demand/withdraw pattern of communication as a predictor of 
marital satisfaction over time: Unresolved issues and future directions. Human Communication Research, 28, 49-85.

Caughlin, J. P., \& Malis, R. S. (2004a). Demand/withdraw communication between parents and adolescents as a correlate of relational satisfaction. Communication Reports, 17, 59-71.

Caughlin, J. P., \& Malis, R. S. (2004b). Demand/withdraw communication between parents and adolescents: Connections with self-esteem and substance use. Journal of Social and Personal Relationships, 21, 125-148.

Caughlin, J. P., \& Vangelisti, A. L. (1999). Desire for change in one's partner as a predictor of the demand/withdraw pattern of marital communication. Communication Monographs, 66, 66-89.

Caughlin, J. P., \& Vangelisti, A. L. (2000). An individual difference explanation of why married couples engage in the demand/withdraw pattern of conflict. Journal of Social and Personal Relationships, 17, 523-551.

Christensen, A. (1988). Dysfunctional interaction patterns in couples. In P. Noller \& M. A. Fitzpatrick (Eds.), Perspectives on marital interaction (pp. 31-52). Philadelphia, PA: Multilingual Matters.

Cialdini, R. B., \& Richardson, K. D. (1980). Two indirect strategies of image management: Basking and blasting. Journal of Personality and Social Psychology, 39, 406-415.

Cody, M. J., \& McLaughlin, M. L. (1980). Perceptions of compliance gaining situations: A dimensional analysis. Communication Monographs, 47, 132-149.

Cole, J. G., \& McCroskey, J. C. (2003). The association of perceived communication 
apprehension, shyness, and verbal aggression with perceptions of source credibility and affect in organizational and interpersonal contexts. Communication Quarterly, 51, 101-110.

Craig, R. T., Tracy, K., \& Spisak, F. (1986). The discourse of requests: Assessment of politeness approach. Human Communication Research, 12, 437-468.

deTurck, M. A. (1985). A transactional analysis of compliance gaining behavior: Effects of noncompliance, relational contexts, and actors' gender. Human Communication Research, 12, 54-78

deTurck, M. A. (1987). When communication fails: Physical aggression as a compliance gaining strategy. Communication Monographs, 54, 106-112.

Dunleavy, K. N., \& Myers, S. A. (April, 2006). The development of a typology of student nagging behavior. Paper presented at the annual meeting of the Eastern Communication Association, Philadelphia.

Emmer, E. T., \& Evertson, C. M. (1981). Synthesis of research on classroom management. Educational Leadership, 38, 342-347.

Festinger, L. (1957). A Theory of Cognitive Dissonance. Stanford, CA: Stanford University Press.

Frey, L. R., Botan, C. H., \& Kreps, G. L. (2000). Investigating communication: An introduction to research methods. Boston: Allyn \& Bacon.

Frymier, A. B. (2005). Students' classroom communication effectiveness. Communication Quarterly, 53, 197-212.

Frymier, A. B., \& Houser, M. L. (2000). The teacher-student relationship as an interpersonal relationship. Communication Education, 49, 207-219. 
Goffman, E. (1963). Stigma: Notes on the management of spoiled identity. New York: Simon and Schuster, Inc.

Goldsmith, D. J., \& Macgeorge, E. L. (2000). The impact of politeness and relationship on perceived quality of advice about a problem. Human Communication Research, 26, 234-263.

Golish, T. D. (1999). Students' use of compliance gaining strategies with graduate teaching assistants: Examining the other end of the power spectrum. Communication Quarterly, 47, 12-32.

Grant, J. A., King, P. E., \& Behnke, R. R. (1994). Compliance gaining strategies, communication satisfaction, and willingness to comply. Communication Reports, 7, 99-108.

Hunter, J. E., \& Boster, F. J. (1987). A model of compliance-gaining message selection. Communication Monographs, 54, 63-84.

Ifert, D. E., \& Roloff, M. E. (1996a). Responding to refusals of requests: The role of requester sex on persistence. Communication Reports, 9, 119-126.

Ifert, D. E., \& Roloff, M. E. (1996b). Responding to rejected requests: Persistence and response type as functions of obstacles to compliance. Journal of Language and Social Psychology, 15, 40-58.

Johnson, D. I., Roloff, M. E., \& Riffee, M. A. (2004a). Politeness theory and refusals of requests: Face threat as a function of expressed obstacles. Communication Studies, 55, 227-238.

Johnson, D. I., Roloff, M. E., \& Riffee, M. A. (2004b). Responses to refusals of requests: 
Face threat and persistence, persuasion and forgiving statements. Communication Quarterly, 52, 347-356.

Kearney, P., \& Plax, T. G. (1992). Student resistance to control. In V. P. Richmond \& J. C. McCroskey (Eds.), Power in the classroom: Communication, control, and concern (pp. 85-100). Hillsdale, NJ: Erlbaum.

Kearney, P., Plax, T. G., \& Burroughs, N. F. (1991). An attribuational analysis of college students' resistance decisions. Communication Education, 40, 325-342.

Kearney, P., Plax, T. G., Sorensen, G., \& Smith, V. R. (1988). Experienced and prospective teachers' selections of compliance gaining messages for "common" student misbehaviors. Communication Education, 37, 150-164.

Kelly, L., Keaten, J. A., \& Finch, C. (2004). Reticent and non-reticent college students' preferred communication channels for interacting with faculty. Communication Research Reports, 21, 197-209.

Kerssen-Griep, J. (2001). Teacher communication activities relevant to student motivation: Classroom facework and instructional communication competence. Communication Education, 50, 256-273.

Kerssen-Griep, J., Hess, J. A., Trees, A. R. (2003). Sustaining the desire to learn: Dimensions of perceived instructional facework related to student involvement and motivation to learn. Western Journal of Communication, 67, 357-381.

King, P. E. (2001). Automatic responses, target resistance, and the adaptation of compliance-seeking requests. Communication Monographs, 68, 386-399.

Kowalski, R. M. (1996). Complaints and complaining: Functions, antecedents and consequences. Psychological Bulletin, 119, 179-196. 
Kozloff, M. A. (1988). Productive interaction with students, children and clients. Springfield, IL: Charles Thomas.

Lindlof, T. R., \& Taylor, B. C. (2002). Qualitative communication research methods. Thousand Oaks, CA: Sage.

McCullough, M. E., Bellah, C. G., Kilpatrick, S. D., \& Johnson, J. L. (2001). Vengefulness: Relationships with forgiveness, rumination, well-being, and the big five. Personality and Social Psychology Bulletin, 27, 601-610.

McManus, K. (2002). Management by nagging (a lot). Institute of Industrial Engineers Solutions, 34, 19.

McCroskey, J. C., \& Richmond, V. P. (1983). Power in the classroom I: Teacher and student perceptions. Communication Education, 32, 175-184.

McNeal, J. U. (1992). Kids as customers: A handbook of marketing to children. New York: Lexington Books.

McPherson, M. B., \& Young, S. L. (2004). What students think when teachers get upset: Fundamental attribution error and student-generated reasons for teacher anger. Communication Quarterly, 52, 357-369.

Miller, G., Boster, F., Roloff, M., \& Seibold, D. (1977). Compliance-gaining message strategies: Typology and some findings concerning effects of situational differences. Communication Monographs, 44, 37-51.

Plax, T. G., Kearney, P., \& Tucker, L. K. (1986). Prospective teachers' use of behavior alteration techniques on common student misbehaviors. Communication Education, 35, 32-42.

Pruitt, D. G., Parker, J. C., \& Mikolic, J. M. (1997). Escalation as a reaction to persistent 
annoyance. International Journal of Conflict Management, 8, 252-270.

Roach, K. D. (1998). Teaching assistant communication apprehension, willingness to communicate, and state communication anxiety in the classroom. Communication Research Reports, 15, 130-140.

Rowan, J. (1997). Men and women are different. British Journal of Guidance \& Counseling, 25, 539-544.

Rubin, R. B., Graham, E. E., \& Mignerey, J. T. (1990). A longitudinal study of college students' communication competence. Communication Education, 39, 1-14.

Sabee, C. M., \& Wilson, S. R. (2005). Students' primary goals, attributions, and facework during conversations about disappointing grades. Communication Education, 54, 185-204.

Scholsser, E. (2002). Fast food nation: The dark side of the All-American meal. New York: HarperCollins Publishers, Inc.

Schrodt, P. (2003). Student perceptions of instructor verbal aggressiveness: The influence of student verbal aggressiveness and self-esteem. Communication Research Reports, 20, 240-250.

Simonds, C. J. (1997). Challenge behavior in the college classroom. Communication Research Reports, 14, 481-492.

Soule, K. P. (2001). Persistence in compliance gaining interactions: The role of nagging behavior. Unpublished doctoral dissertation, Northwestern University.

Soule, K. P. (2006). The what, when, who, and why of nagging in interpersonal relationships. In K. M. Galvin \& P. J. Cooper (Eds.), Making connections: Readings in relational communication (pp. 181-187). Los Angeles, CA: Roxbury. 
Sprague, J. (1993). Retrieving the research agenda for communication education: Asking the pedagogical questions that are "embarrassments to theory." Communication Education, 42, 106-122.

Strauss, A. L., \& Corbin, J. M. (1998). Basics of qualitative research: Techniques and procedures for developing grounded theory. Thousand Oaks, CA: Sage.

Tannen, D. (1990). You just don't understand: Women and men in conversation. New York: William Morrow and Company, Inc.

Taylor, D. A., \& Altman, I. (1973). Social penetration: The development of interpersonal relationships. New York: Hot, Rinehart \& Winston.

Verhofstadt, L. L., Buysse, A., DeClercq, A., \& Goodwin, R. (2005). Emotional arousal and negative affect in marital conflict: The influence of gender, conflict structure, and demand-withdraw. European Journal of Social Psychology, 35, 449-467.

Weger, H. (2005). Disconfirming communication and self-verification in marriage: Associations among the demand/withdraw interaction pattern, feeling understood, and marital satisfaction. Journal of Social and Personal Relationships, 22, 19-31.

Wheeless, L. R., Barraclough, R., \& Stewart, R. (1983). Compliance gaining and power in persuasion. In R. Bostrom (Ed.), Communication Yearbook 7 (pp. 105-145). Beverly Hills, CA: Sage.

Wilson, S. R. (2002). Seeking and resisting compliance: Why people say what they do when trying to influence others. London: Sage.

Wilson, S. R., Aleman, C. G., \& Leatham, G. B. (1998). Identity implications of 
influence goals: A revised analysis of face-threatening acts and application to seeking compliance with same-sex friends. Human Communication Research, 25, 64-96.

Wilson, S. R., \& Kunkel, A. W. (2000). Identity implications of influence goals: Similarities in perceived face threats and facework across sex and close relationships. Journal of Language and Social Psychology, 18, 195-221.

Yoshioka, M. R., Thomas, E. J., \& Ager, R. D. (1992). Nagging and other drinking control efforts of spouses of uncooperative alcohol abusers: Assessment and modification. Journal of Substance Abuse, 4, 308-318. 


\section{Appendix A}

\section{Questions Used in Focus Group Discussions}

1. Please provide some background information about yourself as a student; what year you are in and what your major/minor is.

2. Based on the definition of nagging, is this something that you do, or have done, to gain compliance from an instructor?

a. If no, do you know students who do this behavior?

3. Please tell me about a specific instance in which you nagged an instructor (what were the circumstances, did you get what you wanted, did this make you more/less likely to nag in the future)?

4. Based on that specific instance, why were you using nagging? Were there other techniques you tried to do, or were there other things you thought about doing?

5. Think about other instances in which you nagged instructors. Why were you nagging?

a. If you have not nagged, why do you think other students nag?

6. Do you think your reasons why you nag have changed since you began college; do you think you use nagging differently now as compared to in high school?

7. Now I would like to know how one goes about nagging; what strategies are used?

a. What about flattering instructors?

i. How did you go about using this strategy?

ii. Why use this strategy over other strategies?

b. Elicit sympathy?

i. How did you go about using this strategy? 
ii. Why use this strategy over other strategies?

c. Suggest instructor incompetence?

i. How did you go about using this strategy?

ii. Why use this strategy over other strategies?

d. Barrage instructor with requests?

i. How did you go about using this strategy?

ii. Why use this strategy over other strategies?

e. Challenge instructor authority?

i. How did you go about using this strategy?

ii. Why use this strategy over other strategies?

f. Demonstrate frustration with the instructor?

i. How did you go about using this strategy?

ii. Why use this strategy over other strategies?

g. Strike a deal?

i. How did you go about using this strategy?

ii. Why use this strategy over other strategies?

h. Elicit student support?

i. How did you go about using this strategy?

ii. Why use this strategy over other strategies? 
Appendix B

Survey for Study Two

\begin{abstract}
NAGGING is defined as an exchange in which a person makes persistent, nonaggressive requests which contain the same content, of a respondent who fails to comply. Students often report nagging their instructors.
\end{abstract}

\title{
Participants received one of the following descriptions:
}

One nagging strategy is the elicit sympathy nag. This nag is marked by students who engage in a variety of behaviors designed to make the instructor sympathize with students' personal problems. Examples of these behaviors include telling the instructor about large class work load or outside jobs, telling the instructor about family illness or death, and talking about personal illness.

One nagging strategy is the suggest instructor incompetence nag. This nag is marked by students engaging in a variety of misbehaviors which are not appropriate for the college classroom in order to defy the teacher. Examples of these misbehaviors are leaving class early, talking during lecture, and refusing to do work.

One nagging strategy is the elicit student support nag. This nag is marked by students who form coalitions (i.e., "gang up" as a group) in order to state their requests. Examples of these coalitions are crowding the teacher before and after class to ask questions, and forming a group prior to class to plan a confrontation.

One nagging strategy is the barrage instructor with requests nag. This nag is marked by students who constantly make requests for extensions, extra credit, and early dismissal, through email, phone calls, and out-of-classroom visits.

One nagging strategy is the strike a deal nag. This nag is marked by students who bargain with the instructor for some sort of exchange. Examples of these bargains are promising good classroom behavior for extra credit opportunities, offering to complete favors in order to turn in late work, and suggesting the teacher can take off extra points if the student can take a prohibited makeup exam.

One nagging strategy is the demonstrate frustration with the instructor nag. This nag is marked by students who rely on their nonverbal behaviors. Examples of these nonverbal behaviors include rolling eyes, moaning loudly, crying, storming out of the classroom and slamming classroom doors.

One nagging strategy is the flatter instructor nag. This nag is marked by students who engage in a variety of behaviors designed to be perceived as favorable by the instructor. Examples of these behaviors include complimenting the instructor, flirting with the instructor, and pretending to be buddy-buddy with the instructor. 
In the space below, describe in as much detail as possible what you said and did during an exchange in which you used the nag. Also indicate what the instructor said and did. Please be very specific; if possible, use quotations to indicate what you said to your instructor to nag them.

****************************************************************************

\section{Persistence Measurement}

Imagine that you asked your instructor to do something for you, and the instructor agreed with the request. However, it has been a week and the instructor has not done what you asked. Use the scale below to indicate what your next response would be.

$\begin{array}{lllllll}\text { Not at all } & 1 & 2 & 3 & 4 & 5 & \text { Very much so }\end{array}$

1. How likely would you be to ask your instructor again to comply with your

request?

2. Would you be inclined to persist in seeking fulfillment of your request?

3. Do you believe you would continue with your request?

4. Would you persevere in your attempt to attain your request?

5. How confident are you that you would try again to achieve your request?

\section{Compliance-gaining strategies}

Below are sixteen compliance strategies that individuals use in order to influence others. We are NOT interested in whether you use a particular strategy. Of interest here is whether you COULD USE each strategy. If you were trying to convince a friend to comply with your request, please rate for each strategy how confident you would feel in using each strategy. In the space provided, put your answer in percentages, from $0 \%$ to $100 \%$. If you are totally confident, you would put $100 \%$. If you were barely, or not at all confident, you might put $5 \%$ or $0 \%$.

1. If you comply, I will reward you.

2. If you do not comply I will punish you.

3. If you comply you will be rewarded because of "the nature of things." 
4. If you do not comply you will be punished because of the "nature of things."

5. I am friendly and helpful to get my target in "good frame of mind' so that he/she will comply with my request.

6. I reward my target before requesting compliance.

7. I continuously punish my target until he/she complies with my wishes.

8. You owe me because of past favors.

9. You are immoral if you do not comply.

10. You will feel better about yourself if you comply.

11. You will feel better about yourself if you do not comply.

12. A person with "good" qualities would comply.

13. Only a person with "bad" qualities would not comply.

14. I need your compliance very badly, so do it for me.

15. People you value will think better of you if you comply.

16. People you value will think worse of you if you do not comply.

\section{Student Challenge Behavior}

\section{Below is a list of behaviors that students and instructors report occurring in the college classroom. Using the scale below, indicate for each item how often you personally have used the behaviors described.}

$\begin{array}{ccccc}0 & 1 & 2 & 3 & 4 \\ \text { Doesn't } & \text { Almost } & \text { Sometimes } & \text { Often } & \text { Very } \\ \text { Apply } & \text { Never } & & & \text { Often }\end{array}$

1. Are absent excessively and want to make-up work.

2. Question grade on assignments.

3. Question instructor's knowledge of specific content.

4. Question relevance of tasks to everyday life.

5. Want to receive full credit for late work.

6. Beg for higher grades in class. 
7. Attempt to control when a task will be done.

8. Question the importance of subject matter.

9. Offer "off the wall" examples in class discussion.

10. Compare scores with other students.

11. Don't want to participate.

12. Complain that theories are not applicable to real life.

13. Come to class late.

14. Question the fairness of grading.

15. Attempt to embarrass the instructor.

16. Question why class should be required.

17. Talk during class.

18. Argue over test questions.

19. Interrupt instructor to reinforce your own opinion.

20. Question relevance of concepts being discussed in lecture.

\section{Frequency of Student Nagging Behavior}

Below are several ways in which students have indicated that they nag their instructors. For each strategy below, indicate how often you have used the nagging strategy to get an instructor to do something you wanted them to do.

1. The suggest instructor incompetence nag is marked by students engaging in a variety of misbehaviors in order to defy and/or highlight instructor incompetence. Examples of these behaviors include correcting the instructor, making suggestions that other teachers are more effective, talking during lecture, and refusing to do work.

How often have you used this nag with an instructor? (Circle the response that best represents your perception of that statement)

$$
\begin{array}{lllllll}
\text { Never } & 0 & 1 & 2 & 3 & 4 & \text { Always }
\end{array}
$$

2. The elicit student support nag is marked by students who form coalitions (i.e., "gang up" as a group) in order to state their requests. Examples of these coalitions are crowding the teacher before and after class to ask questions, and forming a group prior to class to plan a confrontation.

How often have you used this nag with an instructor?

$$
\begin{array}{lllllll}
\text { Never } & 0 & 1 & 2 & 3 & 4 & \text { Always }
\end{array}
$$


3. The strike a deal nag is marked by students who bargain with the instructor for some sort of exchange. Examples of these bargains are promising good classroom behavior for extra credit opportunities, offering to complete favors in order to turn in late work, and suggesting the teacher can take off extra points if the student can take a prohibited makeup exam.

How often have you used this nag with an instructor?

$$
\begin{array}{lllllll}
\text { Never } & 0 & 1 & 2 & 3 & 4 & \text { Always }
\end{array}
$$

4. The barrage instructor with requests nag is marked by students who constantly make requests for extensions, extra credit, and early dismissal, through email, phone calls, and out-of-classroom visits.

How often have you used this nag with an instructor?

$$
\begin{array}{lllllll}
\text { Never } & 0 & 1 & 2 & 3 & 4 & \text { Always }
\end{array}
$$

5. The demonstrate frustration with the instructor nag is marked by students who rely on their nonverbal behaviors. Examples of these nonverbal behaviors include rolling eyes, moaning loudly, crying, storming out of the classroom and slamming classroom doors.

How often have you used this nag with an instructor?

$$
\begin{array}{lllllll}
\text { Never } & 0 & 1 & 2 & 3 & 4 & \text { Always }
\end{array}
$$

6. The flatter instructor nag is marked by students who engage in a variety of behaviors designed to be perceived as favorable by the instructor. Examples of these behaviors include complimenting the instructor, flirting with the instructor, and pretending to be buddy-buddy with the instructor.

How often have you used this nag with an instructor?

$$
\begin{array}{lllllll}
\text { Never } & 0 & 1 & 2 & 3 & 4 & \text { Always }
\end{array}
$$

7. The elicit sympathy nag is marked by students who engage in a variety of behaviors designed to make the instructor sympathize with students' personal problems. Examples of these behaviors include telling the instructor about large class work load or outside jobs, telling the instructor about family illness or death, and talking about personal illness.

How often have you used this nag with an instructor?

$$
\begin{array}{lllllll}
\text { Never } & 0 & 1 & 2 & 3 & 4 & \text { Always }
\end{array}
$$

8. Sex (circle one): Male Female 
9. Age:

10. College status: First year Sophomore Junior Senior 11. Major: 
Appendix C

Student Version

Survey for Study Three

NAGGING is defined as an exchange in which a person makes persistent, non-

aggressive requests which contain the same content, of a respondent who fails to

comply. Students often report nagging their instructors. Please report on the

following nagging strategies based on your perceptions of students' nagging

behavior.

1. The suggest instructor incompetence nag is marked by students engaging in a variety of misbehaviors in order to defy and/or highlight instructor incompetence. Examples of these behaviors include correcting the instructor, making suggestions that other teachers are more effective, talking during lecture, and refusing to do work.

How often have you used this nag with an instructor? (Circle the response that best represents your perception of that statement)

$\begin{array}{lllllllll}\text { Never } & 1 & 2 & 3 & 4 & 5 & 6 & 7 & \text { Always }\end{array}$

How effective is this nag on an instructor?

$\begin{array}{ccccccccc}\text { Never } & 1 & 2 & 3 & 4 & 5 & 6 & 7 & \begin{array}{c}\text { Always } \\ \text { Effective }\end{array} \\ \text { Effective } & & & & & & & & \text {. }\end{array}$

How appropriate is it to use this nag with an instructor?

$\begin{array}{ccccccccc}\text { Never } & 1 & 2 & 3 & 4 & 5 & 6 & 7 & \begin{array}{c}\text { Always } \\ \text { Appropriate }\end{array} \\ \text { Appropriate } & & & & & & & & \end{array}$

2. The elicit student support nag is marked by students who form coalitions (i.e., "gang up" as a group) in order to state their requests. Examples of these coalitions are crowding the teacher before and after class to ask questions, and forming a group prior to class to plan a confrontation.

How often have you used this nag with an instructor?

$\begin{array}{lllllllll}\text { Never } & 1 & 2 & 3 & 4 & 5 & 6 & 7 & \text { Always }\end{array}$

How effective is this nag on an instructor? 


$\begin{array}{ccccccccc}\begin{array}{c}\text { Never } \\ \text { Effective }\end{array} & 1 & 2 & 3 & 4 & 5 & 6 & 7 & \begin{array}{c}\text { Always } \\ \text { Effective }\end{array}\end{array}$

How appropriate is it to use this nag with an instructor?

$\begin{array}{ccccccccc}\begin{array}{c}\text { Never } \\ \text { Appropriate }\end{array} & 1 & 2 & 3 & 4 & 5 & 6 & 7 & \begin{array}{c}\text { Always } \\ \text { Appropriate }\end{array} \\ \end{array}$

3. The strike a deal nag is marked by students who bargain with the instructor for some sort of exchange. Examples of these bargains are promising good classroom behavior for extra credit opportunities, offering to complete favors in order to turn in late work, and suggesting the teacher can take off extra points if the student can take a prohibited makeup exam.

How often have you used this nag with an instructor?

$\begin{array}{lllllllll}\text { Never } & 1 & 2 & 3 & 4 & 5 & 6 & 7 & \text { Always }\end{array}$

How effective is this nag on an instructor?

$\begin{array}{ccccccccc}\begin{array}{c}\text { Never } \\ \text { Effective }\end{array} & 1 & 2 & 3 & 4 & 5 & 6 & 7 & \begin{array}{c}\text { Always } \\ \text { Effective }\end{array}\end{array}$

How appropriate is it to use this nag with an instructor?

$\begin{array}{ccccccccc}\begin{array}{c}\text { Never } \\ \text { Appropriate }\end{array} & 1 & 2 & 3 & 4 & 5 & 6 & 7 & \begin{array}{c}\text { Always } \\ \text { Appropriate }\end{array} \\ \end{array}$

4. The barrage instructor with requests nag is marked by students who constantly make requests for extensions, extra credit, and early dismissal, through email, phone calls, and out-of-classroom visits.

How often have you used this nag with an instructor?

$\begin{array}{lllllllll}\text { Never } & 1 & 2 & 3 & 4 & 5 & 6 & 7 & \text { Always }\end{array}$

How effective is this nag on an instructor?

$\begin{array}{ccccccccc}\begin{array}{c}\text { Never } \\ \text { Effective }\end{array} & 1 & 2 & 3 & 4 & 5 & 6 & 7 & \begin{array}{c}\text { Always } \\ \text { Effective }\end{array}\end{array}$

How appropriate is it to use this nag with an instructor?

$\begin{array}{ccccccccc}\text { Never } & 1 & 2 & 3 & 4 & 5 & 6 & 7 & \begin{array}{c}\text { Always } \\ \text { Appropriate }\end{array} \\ \text { Appropriate } & & & & & & \end{array}$


5. The demonstrate frustration with the instructor nag is marked by students who rely on their nonverbal behaviors. Examples of these nonverbal behaviors include rolling eyes, moaning loudly, crying, storming out of the classroom and slamming classroom doors.

How often have you used this nag with an instructor?

$\begin{array}{llllllllll}\text { Never } & 1 & 2 & 3 & 4 & 5 & 6 & 7 & \text { Always }\end{array}$

How effective is this nag on an instructor?

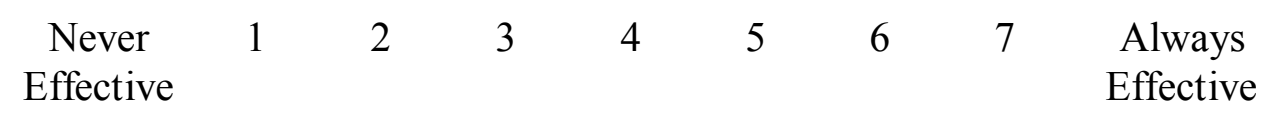

How appropriate is it to use this nag with an instructor?

$\begin{array}{cllllllll}\begin{array}{c}\text { Never } \\ \text { Appropriate }\end{array} & 1 & 2 & 3 & 4 & 5 & 6 & 7 & \begin{array}{c}\text { Always } \\ \text { Appropriate }\end{array} \\ \end{array}$

6. The flatter instructor nag is marked by students who engage in a variety of behaviors designed to be perceived as favorable by the instructor. Examples of these behaviors include complimenting the instructor, flirting with the instructor, and pretending to be buddy-buddy with the instructor.

How often have you used this nag with an instructor?

$\begin{array}{lllllllll}\text { Never } & 1 & 2 & 3 & 4 & 5 & 6 & 7 & \text { Always }\end{array}$

How effective is this nag on an instructor?

$\begin{array}{ccccccccc}\begin{array}{c}\text { Never } \\ \text { Effective }\end{array} & 1 & 2 & 3 & 4 & 5 & 6 & 7 & \begin{array}{c}\text { Always } \\ \text { Effective }\end{array}\end{array}$

How appropriate is it to use this nag with an instructor?

$\begin{array}{cllllllll}\begin{array}{c}\text { Never } \\ \text { Appropriate }\end{array} & 1 & 2 & 3 & 4 & 5 & 6 & 7 & \begin{array}{c}\text { Always } \\ \text { Appropriate }\end{array} \\ \end{array}$

7. The elicit sympathy nag is marked by students who engage in a variety of behaviors designed to make the instructor sympathize with students' personal problems. Examples of these behaviors include telling the instructor about large class work load or outside jobs, telling the instructor about family illness or death, and talking about personal illness.

How often have you used this nag with an instructor? 


$\begin{array}{lllllllll}\text { Never } & 1 & 2 & 3 & 4 & 5 & 6 & 7 & \text { Always }\end{array}$

How effective is this nag on an instructor?

$\begin{array}{ccccccccc}\begin{array}{c}\text { Never } \\ \text { Effective }\end{array} & 1 & 2 & 3 & 4 & 5 & 6 & 7 & \begin{array}{c}\text { Always } \\ \text { Effective }\end{array}\end{array}$

How appropriate is it to use this nag with an instructor?

$\begin{array}{ccccccccc}\text { Never } & 1 & 2 & 3 & 4 & 5 & 6 & 7 & \begin{array}{c}\text { Always } \\ \text { Appropriate }\end{array} \\ \text { Appropriate } & & & & & & & & \end{array}$

8. Sex (circle one): Male Female

9. Age:

10. College status: First year Sophomore Junior Senior Graduate

11. Major:

Instructor Version

NAGGING is defined as an exchange in which a person makes persistent, nonaggressive requests which contain the same content, of a respondent who fails to comply. Students often report nagging their instructors. As an instructor, please report on the following nagging strategies based on your perceptions of student nagging.

1. The suggest instructor incompetence nag is marked by students engaging in a variety of misbehaviors in order to defy and/or highlight instructor incompetence. Examples of these behaviors include correcting the instructor, making suggestions that other teachers are more effective, talking during lecture, and refusing to do work.

How often do students use this nag with instructors? (Circle the response that best represents your perception of that statement)

$\begin{array}{lllllllll}\text { Never } & 1 & 2 & 3 & 4 & 5 & 6 & 7 & \text { Always }\end{array}$

How effective is this nag on an instructor?

$\begin{array}{ccccccccc}\begin{array}{c}\text { Never } \\ \text { Effective }\end{array} & 1 & 2 & 3 & 4 & 5 & 6 & 7 & \begin{array}{c}\text { Always } \\ \text { Effective }\end{array}\end{array}$

How appropriate is it to use this nag with an instructor? 


$\begin{array}{ccccccccc}\text { Never } & 1 & 2 & 3 & 4 & 5 & 6 & 7 & \begin{array}{c}\text { Always } \\ \text { Appropriate }\end{array} \\ \text { Appropriate } & & & & & & & \end{array}$

2. The elicit student support nag is marked by students who form coalitions (i.e., "gang up" as a group) in order to state their requests. Examples of these coalitions are crowding the teacher before and after class to ask questions, and forming a group prior to class to plan a confrontation.

How often do students use this nag with instructors?

$\begin{array}{llllllllll}\text { Never } & 1 & 2 & 3 & 4 & 5 & 6 & 7 & \text { Always }\end{array}$

How effective is this nag on an instructor?

$\begin{array}{ccccccccc}\begin{array}{c}\text { Never } \\ \text { Effective }\end{array} & 1 & 2 & 3 & 4 & 5 & 6 & 7 & \begin{array}{c}\text { Always } \\ \text { Effective }\end{array}\end{array}$

How appropriate is it to use this nag with an instructor?

$\begin{array}{lllllllll}\text { Never } & 1 & 2 & 3 & 4 & 5 & 6 & 7 & \begin{array}{c}\text { Always } \\ \text { Appropriate }\end{array} \\ \text { Appropriate } & & & & & & & & \end{array}$

3. The strike a deal nag is marked by students who bargain with the instructor for some sort of exchange. Examples of these bargains are promising good classroom behavior for extra credit opportunities, offering to complete favors in order to turn in late work, and suggesting the teacher can take off extra points if the student can take a prohibited makeup exam.

How often do students use this nag with instructors?

$\begin{array}{lllllllll}\text { Never } & 1 & 2 & 3 & 4 & 5 & 6 & 7 & \text { Always }\end{array}$

How effective is this nag on an instructor?

$\begin{array}{ccccccccc}\begin{array}{c}\text { Never } \\ \text { Effective }\end{array} & 1 & 2 & 3 & 4 & 5 & 6 & 7 & \begin{array}{c}\text { Always } \\ \text { Effective }\end{array} \\ \end{array}$

How appropriate is it to use this nag with an instructor?

$\begin{array}{ccccccccc}\text { Never } & 1 & 2 & 3 & 4 & 5 & 6 & 7 & \begin{array}{c}\text { Always } \\ \text { Appropriate }\end{array} \\ \text { Appropriate } & & & & & & & & \end{array}$

4. The barrage instructor with requests nag is marked by students who constantly make requests for extensions, extra credit, and early dismissal, through email, phone calls, and out-of-classroom visits. 
How often do students use this nag with instructors?

$\begin{array}{lllllllll}\text { Never } & 1 & 2 & 3 & 4 & 5 & 6 & 7 & \text { Always }\end{array}$

How effective is this nag on an instructor?

$\begin{array}{ccccccccc}\begin{array}{c}\text { Never } \\ \text { Effective }\end{array} & 1 & 2 & 3 & 4 & 5 & 6 & 7 & \begin{array}{c}\text { Always } \\ \text { Effective }\end{array}\end{array}$

How appropriate is it to use this nag with an instructor?

$\begin{array}{ccccccccc}\begin{array}{c}\text { Never } \\ \text { Appropriate }\end{array} & 1 & 2 & 3 & 4 & 5 & 6 & 7 & \begin{array}{c}\text { Always } \\ \text { Appropriate }\end{array} \\ \end{array}$

5. The demonstrate frustration with the instructor nag is marked by students who rely on their nonverbal behaviors. Examples of these nonverbal behaviors include rolling eyes, moaning loudly, crying, storming out of the classroom and slamming classroom doors.

How often do students use this nag with instructors?

$\begin{array}{lllllllll}\text { Never } & 1 & 2 & 3 & 4 & 5 & 6 & 7 & \text { Always }\end{array}$

How effective is this nag on an instructor?

$\begin{array}{ccccccccc}\begin{array}{c}\text { Never } \\ \text { Effective }\end{array} & 1 & 2 & 3 & 4 & 5 & 6 & 7 & \begin{array}{c}\text { Always } \\ \text { Effective }\end{array}\end{array}$

How appropriate is it to use this nag with an instructor?

$\begin{array}{ccccccccc}\begin{array}{c}\text { Never } \\ \text { Appropriate }\end{array} & 1 & 2 & 3 & 4 & 5 & 6 & 7 & \begin{array}{c}\text { Always } \\ \text { Appropriate }\end{array} \\ \text { Apprian }\end{array}$

6. The flatter instructor nag is marked by students who engage in a variety of behaviors designed to be perceived as favorable by the instructor. Examples of these behaviors include complimenting the instructor, flirting with the instructor, and pretending to be buddy-buddy with the instructor.

How often do students use this nag with instructors?

$\begin{array}{lllllllll}\text { Never } & 1 & 2 & 3 & 4 & 5 & 6 & 7 & \text { Always }\end{array}$

How effective is this nag on an instructor?

$\begin{array}{ccccccccc}\begin{array}{c}\text { Never } \\ \text { Effective }\end{array} & 1 & 2 & 3 & 4 & 5 & 6 & 7 & \begin{array}{c}\text { Always } \\ \text { Effective }\end{array} \\ \end{array}$


How appropriate is it to use this nag with an instructor?

$\begin{array}{ccccccccc}\begin{array}{c}\text { Never } \\ \text { Appropriate }\end{array} & 1 & 2 & 3 & 4 & 5 & 6 & 7 & \begin{array}{c}\text { Always } \\ \text { Appropriate }\end{array}\end{array}$

7. The elicit sympathy nag is marked by students who engage in a variety of behaviors designed to make the instructor sympathize with students' personal problems. Examples of these behaviors include telling the instructor about large class work load or outside jobs, telling the instructor about family illness or death, and talking about personal illness.

How often do students use this nag with instructors?

$\begin{array}{lllllllll}\text { Never } & 1 & 2 & 3 & 4 & 5 & 6 & 7 & \text { Always }\end{array}$

How effective is this nag on an instructor?

$\begin{array}{ccccccccc}\begin{array}{c}\text { Never } \\ \text { Effective }\end{array} & 1 & 2 & 3 & 4 & 5 & 6 & 7 & \begin{array}{c}\text { Always } \\ \text { Effective }\end{array}\end{array}$

How appropriate is it to use this nag with an instructor?

$\begin{array}{ccccccccc}\begin{array}{c}\text { Never } \\ \text { Appropriate }\end{array} & 1 & 2 & 3 & 4 & 5 & 6 & 7 & \begin{array}{c}\text { Always } \\ \text { Appropriate }\end{array} \\ \end{array}$

18. Sex (circle one): Male Female

19. Rank as an instructor (circle one): Adjunct Assistant Professor

Associate Professor Full Professor Emeritus Other

20. Years of experience:

21. Department: 